\title{
Gestión deL PASTOREO: CONOCIMIENTOS Y PRÁCTICAS DE MANEJO DE LAS ESPECIES FORRAJERAS EN LA GANADERÍA trashumante de Iruya (Salta, Argentina)
}

\author{
GRAZING MANAGEMENT: KNOWLEDGE AND PRACTICES OF FODDER SPECIES \\ MANAGEMENT IN TRANSHUMANT LIVESTOCK FARMING IN IRUYA (SALTA, \\ Argentina)
}

Laura M. Califano ${ }^{1}$ (D)

1. Instituto Nacional de Tecnología Agropecuaria, Estación Experimental Agropecuaria Abra Pampa, Agencia de Extensión Rural Humahuaca (Jujuy, Argentina).

*califano.laura@inta.gob.ar / laucalifano@gmail.com

Citar este artículo

CALIFANO, L. M. 2020. Gestión del pastoreo: conocimientos y prácticas de manejo de las especies forrajeras en la ganadería trashumante de Iruya (Salta, Argentina). Bol. Soc. Argent. Bot 55: 493-513.

DOI: https://doi. org/10.31055/1851.2372.v55. n3.28119

\section{SUMMARY}

Background and aims: In the NW of Argentina, Iruya (Salta, Arg.), there are systems of subsistence with cattle extensive management of grazing by family units. They have peasant characteristics, traditional management guidelines, community agreements and a strategy of transhumance in the use of different environmental units.

M\&M: Ethnobiological methodology was used to record the manifestations of the biocultural system, the analysis is qualitative with quantitative contributions in the interpretation of the data.

Results: Eighty-one ethnospecies were identified between wild and cultivated, two vernacular classification systems (one for cattle management and others for forage resource management). A scheme of the availability of fodder in the annual cycle was constructed, based on the supplementation strategies. A livestock management system was observed with two levels of management, one private by the families and the other by the community organization.

Conclusions: The livestock for his society is a practice of subsistence, from the management of environmental units and their resources; their knowledge of the natural environment influences the interaction between vegetables.

\section{Key Words}

Environmental management, ethnobiology, family units, supplementation strategies, traditional practices, vernacular classification.

\section{RESUMEN}

Introducción y objetivos: En el NO de Argentina, Iruya (Salta, Arg.), se encuentran sistemas ganaderos de subsistencia con manejo extensivo del pastoreo a cargo de unidades familiares. Poseen características campesinas, pautas de manejo tradicionales de raigambre andina, acuerdos comunitarios y una estrategia de trashumancia en el uso de diferentes unidades ambientales.

M\&M: Se empleó metodología etnobiológica, para registrar las manifestaciones del sistema biocultural abordado; con análisis cualitativo y aportes cuantitativos.

Resultados: Se identificaron 81 etnoespecies entre silvestres y cultivadas, dos sistemas clasificatorios vernáculos (uno de manejo ganadero bovino y otros para los recursos forrajeros). Se propone un esquema de disponibilidad de forrajera en el ciclo anual, en base a las estrategias de suplementación y un sistema de gestión de la ganadería con dos niveles de manejo (particular y comunitario).

Conclusiones: Los ganaderos realizan el manejo de unidades ambientales y sus recursos; su conocimiento del medio natural influye en la interacción entre vegetales, animales y personas.

\section{Palabras clave}

Clasificación vernácula, estrategias de suplementación, etnobiología, manejo del ambiente, prácticas tradicionales, unidades familiares. 


\section{INTRODUCCIÓN}

En la pre-cordillera y cordillera de los Andes del NO de Argentina se encuentran sistemas de subsistencias basados en la ganadería extensiva con un manejo del pastoreo a cargo de unidades familiares; entre sus características se encuentran tener rasgos campesinos, pautas de manejo tradicionales y acuerdos comunitarios (Ottonello de Reinoso \& Ruthsatz, 1982; Merlino \& Rabey, 1983; Merlino \& Sanchez Proaño, 1996; Göbel, 2001, 2002; Quiroga Mendiola, 2004, 2011; Paz et al., 2012; Califano \& Echazu, 2013). En estos sistemas la trashumancia es usual como práctica productiva, por lo cual comprender su funcionamiento y características constituye motivo de estudio y sistematización (Bocco de Abeya, 1988; Bendini et al., 1994; Galafassi, 1994; Greco, 1995; Escolar, 1996; Maffia \& Zubrzycki, 1999). La trashumancia es descripta como una forma productiva particular de zonas con clima mediterráneo frío; tratándose de un desplazamiento recurrente, pendular y funcional que realizan los pastores con el ganado, cuya periodicidad está regulada por el ritmo cíclico de las estaciones y las actividades desarrolladas por las unidades domésticas (Bendini et al., 2004). En el NO de Argentina se desarrolla en diferentes modalidades, pero usualmente se trata un movimiento estacional y periódico entre unidades ambientales ubicadas a distintas altitudes; cuyo propósito es sostener la disponibilidad de pasturas y agua en un ciclo productivo anual. Estos movimientos han sido registrados y descriptos en la cordillera oriental de Jujuy y Salta, siendo más notable en el manejo del ganado bovino que muestra la mayor movilidad altitudinal y distancias de recorrido (Sturzenegger, 1982; Levy Hynes, 1994; Hilgert, 1998, 2007a; Reboratti, 1998; Quiroga Mendiola, 2000; Hocsman, 2011; Echazú et al., 2016; Califano, 2020).

La importancia que reviste la producción ganadera en la Argentina ha conducido al estudio de los conocimientos locales referidos a la vegetación y su relación con la ganadería; tal es así que existen trabajos referidos a la utilización de la vegetación natural como forraje en diferentes regiones del país (Braun Wilke, 1991; Braun Wilke et al., 1999; Scarpa, 2007; Muiño, 2010; Quiroga Mendiola, 2011; Riat, 2012; Califano \& Echazú, 2013; Califano, 2019; Jiménez-Escobar \& Martínez, 2019). También se encuentran estudios referidos a la gestión de los sistemas ganaderos desde perspectivas socio-ecológicas, que plantean la evaluación de su sostenibilidad y persistencia en el tiempo (Domptail \& Easdale, 2013).

Un aspecto relevante en la compresión de estos sistemas de producción lo constituyen las relaciones (interacciones) entre los vegetales empleados como recursos forrajeros y las sociedades o grupos pastoriles que ejercen un manejo sobre ellos. Sin embargo, el rol de las interacciones que se producen entre vegetales, personas y animales domésticos en los sistemas productivos campesinos trashumantes, aún constituye un espacio de investigación que requiere ser abordado a mayor profundidad (Califano, 2020). Más aún, al observar que su persistencia en el tiempo es producto de una construcción histórica, de la repetición de lógicas productivas comunales y colectivas que son desarrolladas en territorios extensos, con aislamiento geográfico, condiciones climáticas adversas u hostiles, a partir de una base de recursos naturales de uso común; aspectos que también han sido descriptos para otras sociedades campesinas ganaderas del país (Paz et al., 2018).

Las estructuras con las cuales usualmente se analiza el manejo de los vegetales en las sociedades tradicionales emplean como principales categorías analíticas la recolección y la agricultura. Pero en los sistemas ganaderos, las interacciones, se presentan no tan solo entre vegetales y personas, los animales domésticos también pasan a formar parte de las mismas. En estos casos las categorías analíticas resultan escasas por existir un gradiente continuo de prácticas posibles entre recolección y agricultura, que incluyen también las interacciones con los animales (Blancas et al., 2010). En ese gradiente se pueden ubicar las interacciones mediadas por la ganadería, que se realizan a través de las prácticas de manejo de los animales.

Se parte del principio de que, para comprender la relación entre los recursos naturales y el desarrollo de estos sistemas de vida, las dimensiones culturales y biológicas son inseparables. Se aborda el análisis desde enfoques centrados en la diversidad biocultural, que considera los modos de hacer localmente situados, fundados en el conocimiento ambiental tradicional y de construcción comunitaria. Estos modos de hacer se encuentran, en parte, basados en la oralidad y se ponen de manifiesto en prácticas y tecnologías, dando lugar a capacidades técnicas que se gestionan de forma comunitaria o 


\section{Califano, L. M. - Manejo de especies forrajeras en Iruya (Salta, Argentina)}

individual (Toledo \& Barrera Bassols, 2008; Lema \& Pochettino, 2012; Bartl, 2019).

Por ello la propuesta del presente estudio es tener en cuenta no solo los usos la vegetación como recurso forrajero, en el sentido de categoría analítica etnobotánica, sino también el conjunto de prácticas puestas en juego por las unidades domésticas pastoriles para el manejo de su sistema ganadero, por constituir una tecnología de gestión del ambiente propia de estas sociedades; y ser de construcción histórica. En este artículo se reconocen las principales etnotaxa involucradas, las categorías vernáculas utilizadas para su clasificación, las prácticas de manejo ganadero implementadas y las percepciones relacionadas al paisaje y sus recursos por parte de los campesinos trashumantes de Iruya (Salta, Argentina).

\section{Materiales y Métodos}

\section{Área de estudio}

El municipio de Iruya se localiza en el NO de la provincia de Salta, Argentina (Fig. 1) y comprende dos unidades geográficas de orientación aproximada $\mathrm{N}-\mathrm{S}$ y de altitud decreciente de $\mathrm{W}$ a E; ellas son la
Cordillera Oriental (CO) y las Sierras Subandinas (SSA). La CO incluye las serranías que alcanzan los 5000 m como las de Santa Victoria y Zenta; por lo cual es un importante límite orográfico que separa al W el altiplano de la región de "Puna" de los valles bajos templados del E de Salta (Reboratti, 1998). Mientras que las SSA alcanzan los $1400 \mathrm{~m}$, son de menor altitud y se localizan al E del departamento. El relieve es sumamente escarpado, con valles fluviales de orientación W-E que vinculan la "Puna", los valles de altura intermedios y las "Yungas" o "Selvas Subtropicales de Montaña". El área pertenece al sistema hidrográfico de la Alta Cuenca del Río Bermejo, en el cual el río Iruya posee un recorrido de $125 \mathrm{~km}$ desde sus nacientes a los $5000 \mathrm{msnm}$ y su desembocadura en el río Pescado a solo $450 \mathrm{msnm}$, en un desnivel altitudinal de 4000 m (Reboratti, 1998; Raffaelli \& Pérez Ayala, 1999).

El departamento Iruya comprende los municipios Iruya e Isla de Cañas, cada uno con diferentes vías de acceso ya que no existe una red vial que permita su comunicación directa, lo que muestra el importante aislamiento geográfico y comunicacional del departamento. El municipio Iruya se restringe a las zonas de mayor altitud

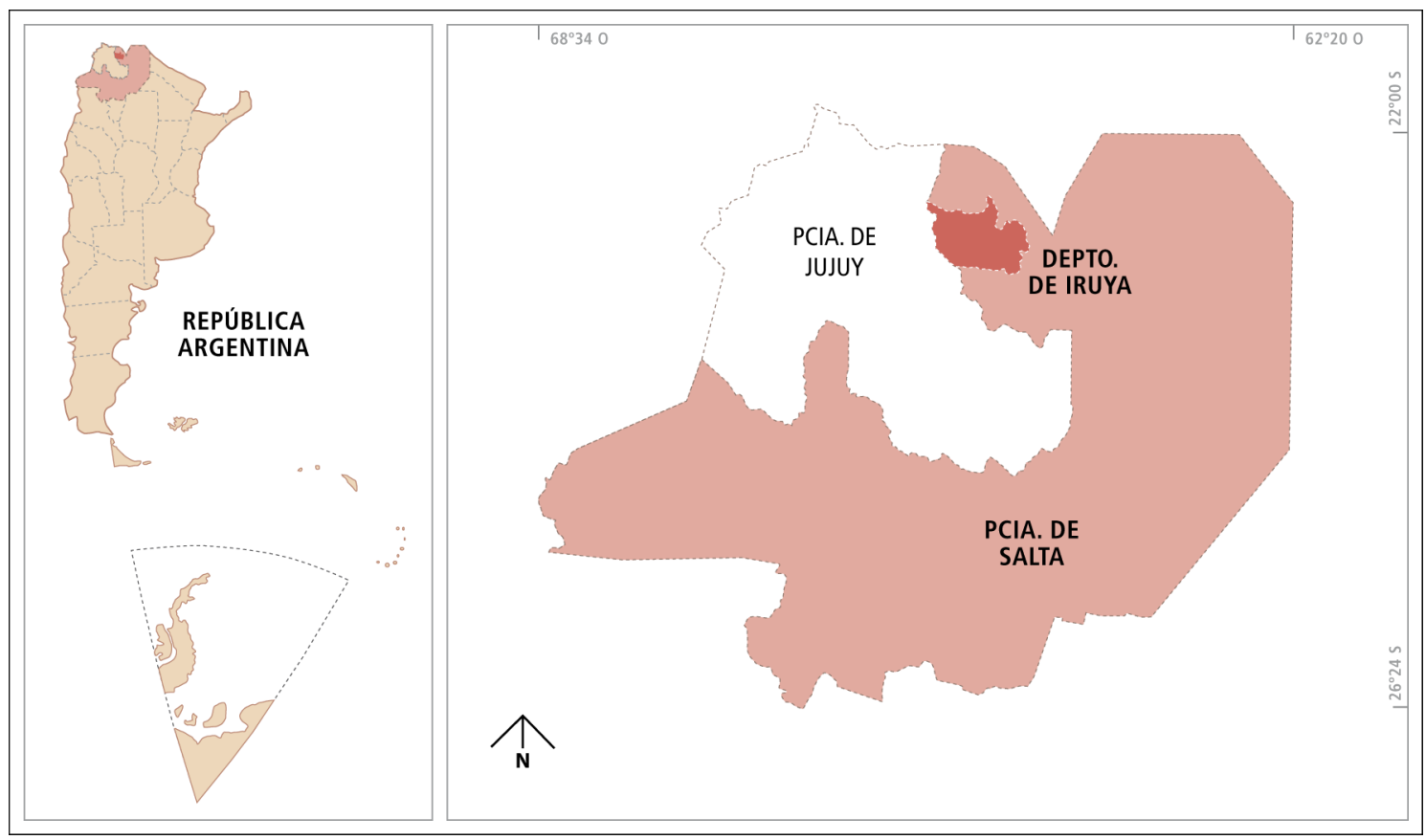

Fig. 1. Ubicación del departamento de Iruya en la provincia de Salta, Argentina. 
del departamento, alrededor de los $2780 \mathrm{msnm}$, mientras que el municipio de Isla de Cañas se encuentra por debajo de los $610 \mathrm{~m}$. El acceso a las poblaciones es sumamente dificultoso, aspecto que redunda en un aislamiento geográfico significativo en amplios sectores del territorio, tal como refieren para otras comunidades de la Alta Cuenca del Río Bermejo (Hilgert, 1998; Ventura \& Belardi, 2001).

El clima del departamento es muy variado, puede ser semiárido de alta montaña en los sectores altos y en las zonas bajas subtropical con estación seca, en general muestra una importante variación producto del gradiente altitudinal, característica de los sistemas montañosos subtropicales. En una altitud media de $2500 \mathrm{msnm}$ la temperatura media máxima oscila entre 16 y $28^{\circ} \mathrm{C}$, y la media mínima entre 8 y $15{ }^{\circ} \mathrm{C}$. A partir de los $3400 \mathrm{msnm}$ la temperatura media decrece entre 7,5 y $9,9^{\circ} \mathrm{C}$, y el clima se vuelve más frío y seco por efecto de los vientos y la altura (Bianchi \& Yañez, 1992; Reboratti, 1998; Raffaelli \& Pérez Ayala, 1999). Las precipitaciones están influenciadas por la orografía, disminuyen de E a O con 1200 mm/año en "Yungas" a 400 mm/ año en "Puna" y "Altoandino"; el patrón anual presenta una estación húmeda de octubre a abril y una estación seca de mayo a setiembre (Bianchi \& Yañez, 1992; Reboratti, 1998).

El área presenta la convergencia de diferentes provincias fitogeográficas, sectores pertenecientes a la provincia fitogeográfica de "Yungas", "Selvas Subtropicales de Montaña" o "Selvas TucumanoOranenses" (Ragonese, 1967; Cabrera, 1976; Cabrera \& Willink, 1980) que en su límite inferior (450-550 msnm) se observa la transición con formaciones chaqueñas, y en su límite superior (aprox. $2700 \mathrm{msnm}$ ) ecotonos con formaciones pertenecientes a las provincias "Prepuna", "Puna" y "Altoandina".

Los productores de Iruya poseen una percepción vertical del ambiente como es usual en las sociedades andinas (Troll, 1935, 1973; Murra, 1975) y ya fuera descripta en la CO (Sturzenegger, 1982; Levy Hynes, 1994; Reboratti, 1998; Hilgert, 1998, 1999, 2004, 2007a, b; Quiroga Mendiola, 2000; Califano, 2020). Como criterio de separación entre las unidades de paisaje (UP) toman en cuenta las características fisonómicas de la vegetación, por ejemplo, la presencia de árboles que forman un bosque o una selva. Reconocen tres UP diferenciables entre sí: "cerro", "valle" y "monte".
El "monte" se corresponde a los pisos ecológicos de "Selva Montana" y "Bosque Montano" de las "Yungas"; el "valle" corresponde al pastizal de altura o de neblina de la "Yungas" y el "cerro" se corresponde con los pastizales de altura y las estepas de "Puna" y "Prepuna". Estas UP estructuran el ciclo ganadero en un movimiento altitudinal que se realiza entre dos épocas: la "lluviosa" (noviembreabril) y la "seca" (mayo-octubre). La combinación de estos dos aspectos (altitud y períodos de lluvias) son los que caracterizan la trashumancia como estrategia de uso vertical del ambiente en la $\mathrm{CO}$ (Califano, 2020).

La población se considera rural en su totalidad al no existir localidades con más de 2000 habitantes (según los criterios del INDEC), alcanza los 5987 habitantes y representa aproximadamente el 0,7 del total de la provincia de Salta, con una densidad poblacional de $1,7 \mathrm{hab} / \mathrm{km}^{2}$ (INDEC, 2010). Si bien la lengua actual para comunicarse es el español, en el léxico cotidiano, en la fitonimia y toponimia se distinguen vocablos de origen Aymara y Quechua. La religión dominante es el catolicismo que se encuentra presente en sincretismo con las creencias prehispánicas andinas junto a otros cultos como la Iglesia Evangélica y los Testigos de Jehová (Califano, 2019).

Los habitantes de la cuenca del río Iruya son descendientes de grupos indígenas quechuas que luego de la conquista pasaron a constituir una subestructura socioeconómica, manteniendo su carácter de segmento rural étnicamente diferenciado sometido a la encomienda de tributos. De las comunidades indígenas sobrevivientes derivó el campesinado de filiación aborigen, arrendatario de las tierras que habían sido suyas y que quedaron incorporadas a las haciendas (Madrazo, 1981). Por ello la división de las comunidades guarda una estrecha relación con las "haciendas" coloniales que dieron lugar a la definición de las unidades político administrativas actuales (Reboratti, 1998).

La producción característica de las UD se basa fundamentalmente en la combinación de trabajo familiar y tierra, aspectos comunes de todas las sociedades campesinas. Se caracterizan por producir bienes agropecuarios destinados a satisfacer sus necesidades de subsistencia a través de la producción agrícola, ganadera y las producciones artesanales (textiles, cueros, carpintería, entre otras) en un calendario anual. Cada 


\section{Califano, L. M. - Manejo de especies forrajeras en Iruya (Salta, Argentina)}

familia posee un espacio propio para la agricultura que se complementa con espacios dedicados a granja y crianza de ganado (Reboratti, 1998; Quiroga Mendiola, 2000; Hocsman, 2011; Echazu et al., 2013; Califano, 2019, 2020). Las prácticas de subsistencia de las unidades se desarrollan en función de los movimientos entre "cerro", "valle" $\mathrm{y}$ "monte", que es similar a la registrada en zonas aledañas de la cordillera oriental (Sturzenegger; 1982; Hilgert, 1998, 1999, 2004).

\section{Metodología}

Se empleó metodología etnobiológica, para registrar las manifestaciones del sistema biocultural abordado desde la propia perspectiva de los actores (Baptista Lucio et al., 2006; Martínez, 2006; Arenas \& Martínez, 2012); por medio del empleo de técnicas etnográficas: reuniones y talleres con pobladores e informantes calificados, entrevistas exploratorias y en profundidad a informantes clave, recorridas de campo con informantes para colecta de muestras vegetales y observación participante (en ferias, eventos rituales y actividades agropecuarias).

La unidad de análisis es la unidad doméstica (UD), que es definida como un grupo de personas que interactúan en forma cotidiana, regular y permanente, a fin de asegurar mancomunadamente su reproducción biológica, la preservación de su vida, el cumplimiento de todas aquellas prácticas económicas y no económicas indispensables para la optimización de sus condiciones materiales y no materiales de existencia (Archetti \& Stolen, 1975; Torrado, 1981; Cáceres, 2003).

Sobre las 993 Explotaciones registradas por el Censo Nacional Agropecuario del año 2008 (INDEC, 2010) presentes en Iruya, se realizó un muestreo del 7\% mediante una encuesta ad hoc referida a variables de socio-productivas, la misma se acompañó con metodología cualitativa: entrevistas en profundidad a informantes clave, observación participante en procesos productivos colectivos, tanto dentro de ámbitos comunitarios como en las unidades domésticas y sus zonas de pastoreo. La recopilación de información se realizó en 14 comunidades del municipio de Iruya en el período de enero de 2011 a diciembre 2017. Las entrevistas a profundidad se realizaron a 45 informantes clave, en un rango de 30 a 85 años de edad, con diferentes niveles de instrucción; quienes brindaron su acuerdo en participar de la investigación según lo establecen los convenios internacionales y la legislación argentina que los ratifica. Los principales criterios empleados para su selección fueron: haber sido referidos en la comunidad por sus conocimientos sobre la ganadería local, ser originarios de Iruya y haber participado en actividades ganaderas en el transcurso de su vida. Se confeccionó una guía temática para las entrevistas con tópicos referidos al manejo y uso del espacio, de los recursos vegetales, de la ganadería, los significados y percepciones que se otorgan a la actividad ganadera. Las entrevistas tuvieron una duración promedio de 30-60 minutos; fueron en su mayoría individuales $(94 \%)$ y en algunos casos con otro participante interesado. Como la actividad ganadera bovina concentra la mano de obra masculina el $69 \%$ de los informantes fueron hombres. En la sistematización de la información recopilada se tomó como criterio de consenso que al menos dos informantes indicaran sobre el mismo uso de determinada especie vegetal o de otros aspectos de manejo consultados en la entrevista (Scarpa, 2000; Suárez, 2014). Todos los datos e información resultantes se registraron en notas de campo, grabaciones y fotografías.

La identificación de especies fue realizada en primer término con el soporte de las bases de Tropicos (Tropicos, 2019) y Flora del Cono SurFlora Argentina (IBODA, 2018), acompañado con la consulta de la base The Plant List (2013). La colección de referencia se encuentra en el Herbario del Museo de Ciencias Naturales de Salta (MCNS).

Se emplea el término etnoespecies o etnotaxas para representar a los elementos vegetales que son funcionales a las preferencias de uso y a las necesidades locales de esta sociedad (Sánchez et al., 2007; Rosales Bustamante et al., 2009; Lambaré \& Pochettino, 2012). Para registrar la percepción del ambiente natural y su manejo se consideraron las categorías empíricas, denominadas etnocategorías y que aluden a las categorías vernáculas empleadas para referir los diferentes componentes de la clasificación local (Aldunate et al., 1981).

En este trabajo se considera la gestión como aquellas prácticas dirigidas a adaptar o transformar un objeto (un sistema, sus elementos y/o sus procesos) de acuerdo con un plan humano; por lo tanto, los usos de plantas que involucran planes, estrategias, acuerdos y regulaciones deben ser consideradas como gestión según lo plantea Blancas et al. (2010). 


\section{Resultados}

\section{La ganadería del Departamento Iruya}

El sistema se basa en el manejo de dos categorías ganaderas diferenciadas: el ganado bovino (Bos taurus), denominado localmente como "hacienda"; y la segunda categoría constituida por los rumiantes menores caprinos (Capra aegragrus) y ovinos (Ovis orientalis) denominada localmente como "hacienda menuda". Cada una de estas categorías se encuentra relacionada a un patrón de asentamiento típicamente pastoril, donde se distinguen las residencias permanentes de la UD, de las residencias temporarias denominadas "puestos" distribuidos en "parajes de pastoreo".

El manejo de la "hacienda menuda" o ganado menor se basa en mantener los animales pastando todo el año, o gran parte de él, en el mismo paraje usualmente cercano a las viviendas permanentes. Si bien, con estos animales se realizan movimientos entre diferentes sitios de pastoreo, dependen de los puestos ganaderos que posee la UD y de los acuerdos establecidos en la comunidad. Los períodos de permanencia en cada sitio son cortos, de alrededor de dos a cuatro meses; y las distancias promedio de recorrido se cubren en un día de caminata, por tratarse de puestos en sitios de pastoreo cercanos a la vivienda permanente de la UD. Estos rebaños son encerrados diariamente en los corrales para pernoctar y cuidarlos de los predadores: puma (Puma concolor), yaguareté (Panthera onca) y cóndor (Vultur gryphus); cerca del mediodía se los suelta para iniciar el pastoreo diario. Su cuidado es responsabilidad principal de mujeres y niños con la ayuda de perros pastores. Su destino es el autoconsumo de los subproductos: la carne, leche y quesos para consumo directo cotidiano, la lana se emplea para textiles artesanales, el cuero para asientos de sillas y camastros, y también la carne para conservar en forma disecada.

La "hacienda mayor" o ganado vacuno es percibido localmente como de mayor importancia por su alto valor económico y por el tiempo que requiere incrementar la cantidad de animales en un rodeo; es por esto que ser propietario de bovinos confiere cierto prestigio social a la UD. El cuidado de los bovinos recae principalmente en los hombres a partir de los 14 años y no todas las UD poseen bovinos por falta de mano de obra masculina. El principal destino del bovino, no es el autoconsumo, sino la venta en pie o el trueque local para abastecer las carnicerías del pueblo de Iruya y en menor proporción a vecinos de otras comunidades. Los requerimientos de carne del pueblo de Iruya son constantes; tal es así que los carniceros al momento de adquirir los animales no pagan un precio diferenciado por cada categoría bovina (novillos, vaquillas, vacas, toros); la venta usual se realiza por un lote compuesto de animales de diferentes categorías etarias, el precio que se paga es uno solo por lote.

El ganado bovino es sujeto de una clasificación vernácula que lo divide en dos categorías de manejo referidas a su movilidad altitudinal: las vacas "monteñas", que realizan trashumancia al monte, y las vacas "punistas" o "cerreñas" o "costeñas que permanecen todo el año en zonas altas de la UP de cerro.

Se observan prácticas de manejo diferenciadas para estas etnocategorías propias del ganado bovino: "vacas punistas" y "vacas monteñas". La etnocategoría ganadera denominada "punistas, costeñas o cerreñas" posee un manejo donde los movimientos de pastoreo siempre se realizan en parajes de la UP de cerro, transitando por mesetas y filos, cambiando de sitios de pastoreo solamente dentro de este ambiente. Es por ello que los animales quedan todo el año en parajes altos (de más de 2500 msnm) donde pueden pastorear libres o dentro de grandes cerramientos denominados "rastrojos" o "potreros" (de 3 ha. aproximadamente). A los animales se los traslada entre varios cerramientos numerosas veces en el año, existiendo la posibilidad de arrendar el servicio de pastaje en el "rastrojo" a otros productores.

Las "vacas monteñas" pasan en cada UP (cerro/ valle y monte) un promedio de entre seis a siete meses. Desde los meses de abril-mayo a noviembrediciembre los animales que se encuentran en el monte; comienzan su regreso a los ambientes de cerro/valle a partir de las primeras lluvias en noviembre-diciembre y permanecen allí hasta abrilmayo cuando retornan al monte. Los rodeos de "vacas monteñas" pueden estar sujetas a dos tipos de desplazamientos: los realizados únicamente por un cuidador temporal (denominado "vaquero") quien conduce los rodeos al sitio de pastoreo en el monte y realiza controles periódicos dentro de los parajes; el segundo tipo de desplazamiento requiere del movimiento de toda la UD propietaria de los 


\section{Califano, L. M. - Manejo de especies forrajeras en Iruya (Salta, Argentina)}

animales para residir en el monte acompañando su rodeo. Aproximadamente un $70 \%$ de los productores declara no organizarse con otro productor vecino para conducir el rodeo al monte y el traslado de los animales queda a cargo del propietario. Mientras que el $30 \%$ restante se organiza para desplazarse junto a toda la UD para un cambio temporal de residencia, o bien recurre a un arreglo de cuidado con un "vaquero".

Se destaca que entre ambas etnocategorías ("punistas" y "monteñas") los animales no se mezclan, son siempre manejados por separado; la percepción sobre cual es mejor varía según las posibilidades de cada UD, y se evalúa principalmente en base a la dedicación que requieren, a la resistencia de los animales y a la calidad de la carne. Ambas etnocategorías no se relacionan entre sí, tampoco se encuentran en transición desde una etnocategoría a la otra, ya que son considerados animales totalmente diferentes. La percepción local señala que los animales aprenden a comportarse en sus ambientes a partir de la interacción que se da entre ellos desde su nacimiento, por ello una vaca que es "punista" no sabe cómo comportarse en el ambiente de "monte" ya que no lo ha aprendido. Refieren que los animales adquieren sus hábitos producto del aprendizaje y convivencia con los otros animales del rodeo. A los animales les atribuyen la posesión de conocimientos, que son valorados como virtudes y que se espera los terneros adquieran de los animales adultos en un proceso de aprendizaje, entre estos conocimientos se pueden señalar: a) reconocer los sitios de pastoreo de su rodeo; b) percibir la presencia de personas en el puesto -a través del fuego y el humo- para acercarse en busca del suplemento de sal; c) identificar a partir del cambio de temperatura ambiental y la presencia de insectos los momentos del ciclo anual adecuados para desplazarse entre "cerro" y "monte"; d) aprender sobre los sitios donde se encuentran forrajes tóxicos y los sitios donde se localizan forrajes aptos; e) reconocer los sitios seguros donde parir.

Existen UD que poseen las dos etnocategorías ganaderas, esto se debe a que las vacas "punistas" son de cuidado más cercano a las casas permanentes en el ambiente de "cerro" por lo que son menos demandantes de mano de obra masculina y resultan de consumo más inmediato; esto también brinda facilidades al momento de su venta en las UD con pocos integrantes varones. Por el contrario, la venta de las vacas "monteñas" se concentra entre los meses de noviembre a mayo cuando se encuentran en el cerro, los seis meses que pasan en parajes alejados e inaccesibles del monte requieren de una travesía en búsqueda de los animales que resulta complicada para las UD que no tienen integrantes masculinos.

Los caballos (Equus ferus caballus), los asnos (Equus africanus asinus) y las mulas (Equus asinus $\mathrm{x}$ Equus caballus) se crían para transportar cargas y personas en recorridos de gran distancia a comunidades aisladas. Los caballos son menos frecuentes por sus elevados requerimientos alimenticios, ya que requieren de la provisión extra de forraje, pero como se arriendan a otras UD pueden ser una fuente potencial de ingresos.

En Iruya se practica un esquema de trashumancia que integra un gradiente mayor a los $2000 \mathrm{msnm}$, que se basa en el cambio de lugar de pastoreo del ganado bovino entre dos o más sitios de pastoreo localizados en las UP de cerro y de monte. El esquema que se muestra (Fig. 2) permite el aprovechamiento de los recursos vegetales de los distintos pisos altitudinales en diferentes períodos, atenuando el bache forrajero de la estación seca, así como el descanso y recuperación de los ambientes pastoreados.

Para los recursos forrajeros también se observó una clasificación vernácula que evidencia la aplicación de etnocategorías basadas en las prácticas locales de manejo de los mismos y en las percepciones que se tiene de las etnoespecies que las integran. Así como el ambiente se percibe en las UP "cerro", "valle" y "monte"; las especies vegetales presentes en estos ambientes están sujetas a identificaciones y agrupaciones conceptuales locales vinculadas a las prácticas ganaderas que despliegan. Se parte de una distinción principal que separa en primer término los "pastos" o "pasturas naturales" de aquellas que se identifican como "pasturas cultivadas". Es necesario aclarar que, a pesar de utilizar el término "pastura" indistintamente en ambos casos, los campesinos diferencian claramente el grado de intervención humana que hay entre ambas categorías. Para los "pastos" o "pasturas naturales" existe una clasificación vernácula vinculada al uso directo de la vegetación durante el pastoreo. Al referirse a las "pasturas cultivadas" la diferencia la establecen por 


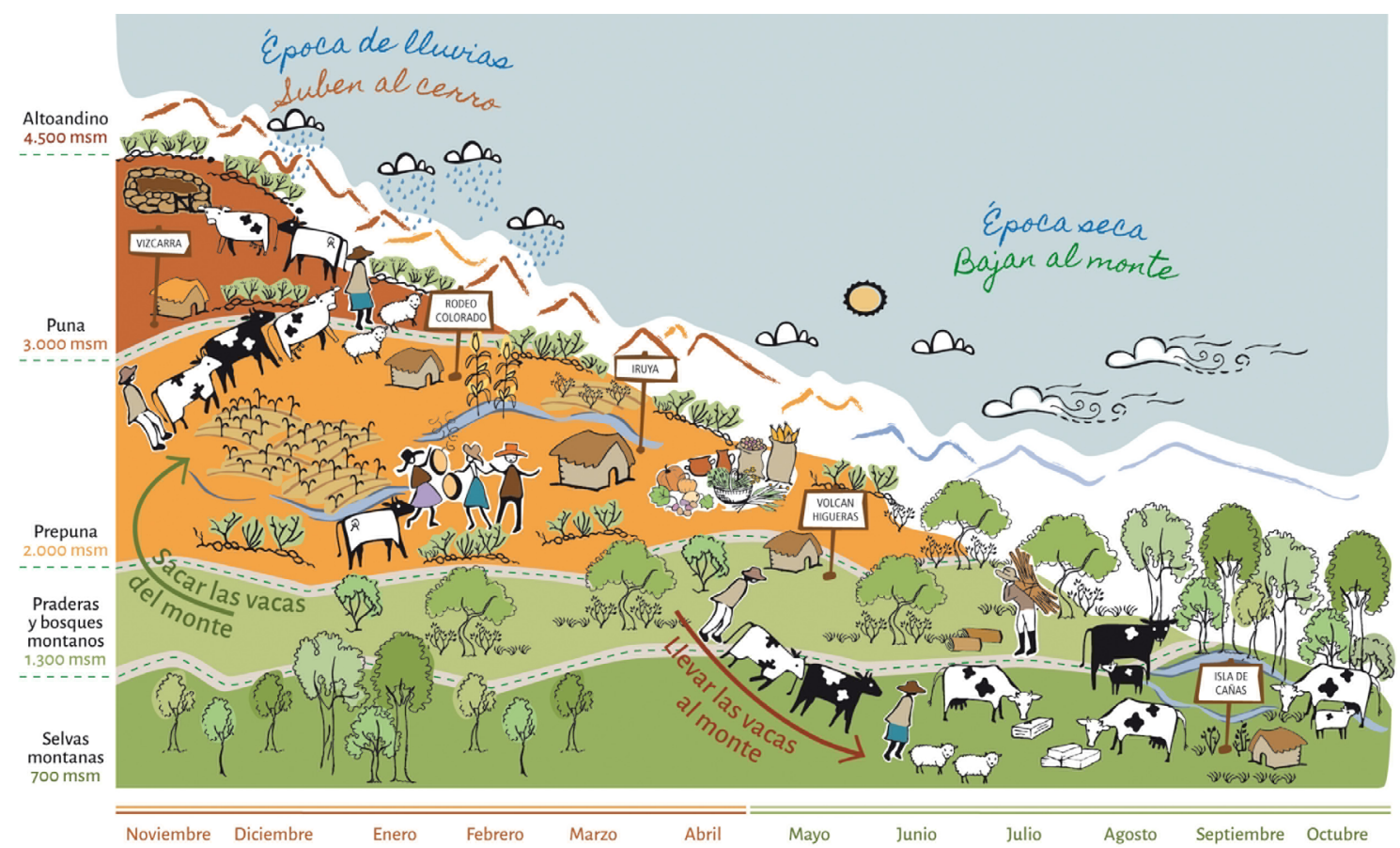

Fig. 2. Esquema de la trashumancia que se practica en Iruya, basada en el cambio de lugar de pastoreo del ganado bovino de la etnocategoría "vacas monteñas" entre las UP "cerro" y "monte".

el requerimiento de intervención humana para su obtención.

\section{Etnoespecies y clasificación vernácula de recursos forrajeros}

Se registraron un total de 81 etnoespecies vinculadas a la ganadería que pertenecen a 23 familias botánicas; las silvestres se mencionan en la Tabla 1 y las obtenidas a través del cultivo en la Tabla 2. Entre las etnoespecies silvestres la familia Poaceae es la mejor representada con 25 $\%$ de especies (18 taxas), seguida de la familia Asteraceae en segundo término con $16 \%$ (12 taxas) y en tercer lugar la familia Lamiaceae con $10 \%$ (7 taxas). Las restantes familias se encuentran representadas por menos del $8 \%$, es decir desde 6 a 1 taxa cada una.

La clasificación vernácula de los recursos forrajeros se encuentra constituida por grupos de etnoespecies reunidas bajo un único nombre colectivo para designar una agrupación donde sus integrantes comparten algún atributo en común. Es por ello que las etnoespecies que poseen uso como forrajeras no son necesariamente identificadas de manera individual, salvo en casos puntuales en los que se percibe alguna característica sobresaliente como: ser especialmente nutritivas, estar disponibles en momentos de gran escasez de forraje, ser muy apetecidas por algún tipo de ganado particular, tener otros usos etnobotánicos conocidos, entre otras.

En el sistema clasificatorio de los recursos forrajeros de Iruya, el término "pastos" es una denominación colectiva y constituye una etnocategoría empleada como homóloga al de forraje. Este término de base se asocia a otros términos que señalan atributos o criterios percibidos como comunes y que permiten diferenciar los grupos entre sí por brindar información sobre sus características; pueden remitir a la fisonomía de sus componentes, al ambiente en el que se encuentran, a la preferencia de consumo del ganado, a su calidad y capacidad nutricional.

Se identificaron diez etnocategorías con nombres colectivos que incluyen grupos de etnoespecies, según muestra la Tabla 3; cuatro categorías aluden a los sitios donde se encuentran estos grupos 
Tabla 1. Principales especies empleadas como forrajes silvestres en Iruya (Salta).

\begin{tabular}{|c|c|c|c|c|}
\hline Familia y Especie & Nombre Local & UP & Voucher & Estatus \\
\hline \multicolumn{5}{|l|}{ AMARANTHACEAE } \\
\hline Amaranthus hybridus L. & $\begin{array}{l}\text { Ataco, Yuyo } \\
\text { colorado }\end{array}$ & Cerro/Monte & CL 365, 389 & Nativa \\
\hline \multicolumn{5}{|l|}{ ASTERACEAE } \\
\hline Aldama helianthoides (Rich.) E.E. Schill. \& Panero & Suncho & Cerro & CL 457 & Nativa \\
\hline Baccharis boliviensis (Wedd.) Cabrera & Tola & Cerro & CL \& EF 192 & Nativa \\
\hline Baccharis dracunculifolia DC. & Tola & Cerro & CL \& BB 331 & Nativa \\
\hline Baccharis sculpta Griseb. & Chilca & Cerro & CL \& BB 332 & Nativa \\
\hline Bidens andicola Kunth & Pante amarillo & Cerro & CL \& BB 305 & Nativa \\
\hline Bidens pilosa L. & Saitilla & Cerro & CL \& BB 309 & Nativa \\
\hline Chuquiraga longiflora (Griseb.) Hieron. & Palo amarillo & Cerro & CL \& BB 344 & Nativa \\
\hline Chuquiraga oppositifolia D. Don & Palo amarillo & Cerro & CL \& BB 310 & Nativa \\
\hline Genero sin determinar & Pasto oveja & Cerro & $\begin{array}{l}C L \& B B \\
303,319\end{array}$ & $s / d$ \\
\hline Mutisia ledifolia Decne. ex. Wedd. & Oque tola & Cerro & CL \& BB 317 & Nativa \\
\hline Tagetes filifolia Lag. & Anis del campo & Cerro & CL 334 & Nativa \\
\hline Zinnia peruviana (L.) L. & Maiquisa & Cerro & CL \& BB 326 & Nativa \\
\hline \multicolumn{5}{|l|}{ BETULACEAE } \\
\hline Alnus acuminata Kunth & Aliso & Monte & HN 1083 & Nativa \\
\hline \multicolumn{5}{|l|}{ BROMALIACEAE } \\
\hline Cf. Deuterocohnia sp. & Taraca & Cerro & CL \& HC 204 & Nativa \\
\hline Puya yakespala A. Cast. & Yasquispala & Cerro & CL \& BB 269 & Nativa \\
\hline Tillandsia australis Mez & Payo & Cerro/Monte & CL \& EF 290 & Nativa \\
\hline Tillandsia tenuifolia L. & Taraca & Cerro & CL 363 & Nativa \\
\hline \multicolumn{5}{|l|}{ EPHEDRACEAE } \\
\hline Ephedra breana Phil. & Pinco, Pingo & Cerro & CL \& BB 328 & Nativa \\
\hline \multicolumn{5}{|l|}{ FABACEAE } \\
\hline Adesmia trijuga Gillies ex Hook. \& Arn. & Añagua & Cerro & CL \& BB 329 & Nativa \\
\hline $\begin{array}{l}\text { Parasenegalia visco (Lorentz ex } \\
\text { Griseb.) Seigler \& Ebinger }\end{array}$ & Yapan & Cerro/Monte & CL \& HC 278 & Nativa \\
\hline Parapiptadenia excelsa (Griseb.) Burk. & Cebil del monte & Monte & PC 709 & Nativa \\
\hline Prosopis ferox Griseb. & Churqui & Cerro & CL 391 & Nativa \\
\hline $\begin{array}{l}\text { Senna birostris (Dombey ex Vogel) } \\
\text { H.S. Irwin \& Barneby }\end{array}$ & Taquillo & Cerro & CL \& BB 327 & Nativa \\
\hline $\begin{array}{l}\text { Vachellia aroma (Gillies ex Hook } \\
\text { \& Arn.) Seigler \& Ebinger }\end{array}$ & Tusca & Cerro/Monte & CL \& HC 216 & Nativa \\
\hline \multicolumn{5}{|l|}{ LAMIACEAE } \\
\hline Clinopodium gilliesii (Benth.) Kuntze & Muña de burro & Cerro & CL 147, 295, 333 & Nativa \\
\hline Clinopodium odorum (Griseb.) Harley & Muña de cabra & Cerro & CL 296, 316, 343 & Nativa \\
\hline Lepechinia meyenii (Walp.) Epling & Salvia guiadora & Cerro & CL 230, 245, 320 & Nativa \\
\hline Lippia turnerifolia Cham. & Pastos de cerro & Cerro/Valle & CL \& EF 235 & Nativa \\
\hline Salvia cuspidata Ruiz \& Pav. & Salvia chica & Cerro & CL 225,28 & Nativa \\
\hline Salvia stachydifolia Benth. & Salvia grande & Cerro & CL 318 & Nativa \\
\hline Verbena hispida Ruiz \& Pav. var. hispida & Verbena & Cerro & CL \& BB 321 & Nativa \\
\hline \multicolumn{5}{|l|}{ MALVACEAE } \\
\hline Malva sylvestris L. & Malva & Cerro & CL \& BB 308 & Naturalizada \\
\hline Malva parviflora L. & Malva & Cerro & CL 367 & Naturalizada \\
\hline
\end{tabular}




\begin{tabular}{|c|c|c|c|c|}
\hline Familia y Especie & Nombre Local & UP & Voucher & Estatus \\
\hline \multicolumn{5}{|l|}{ MELIACEAE } \\
\hline Cedrela angustifolia DC. & Cedro & Monte & $\begin{array}{l}\text { MAZ \& EDC } \\
2350,2405\end{array}$ & Nativa \\
\hline \multicolumn{5}{|l|}{ OXALIDACEAE } \\
\hline Hypseocharis pimpinellifolia J. Remy & Soldaque & Cerro & CL 372 & Nativa \\
\hline \multicolumn{5}{|l|}{ PLANTAGINACEAE } \\
\hline Plantago australis Lam. & Llantén, Yantin & Cerro & CL \& BB 342 & Nativa \\
\hline \multicolumn{5}{|l|}{ POACEAE } \\
\hline Bouteloua curtipendula (Michx.) Torr. & Pastos de cerro & Cerro & CL \& BB 339 & Nativa \\
\hline Cenchrus chilensis (E. Desv.) Morrone & Esporal, Espuro & Cerro & CL 469 & Nativa \\
\hline Chloris halophila Parodi var. halophila & Pastos de cerro & Cerro & CL \& BB 349 & Nativa \\
\hline $\begin{array}{l}\text { Cinnagrostis rigescens (J. Presl) P.M. } \\
\text { Peterson, Soreng, Romasch. \& Barberá }\end{array}$ & Pastos de cerro & Cerro & CL \& EF 265 & Nativa \\
\hline $\begin{array}{l}\text { Cortaderia hieronymi (Kuntze) } \\
\text { N.P. Barker \& H.P. Linder }\end{array}$ & $\begin{array}{l}\text { Sevenguilla } \\
\text { Sivinguilla }\end{array}$ & Cerro/Monte & CL \& EF 244 & Nativa \\
\hline Cortaderia sp. & Cortadera & Cerro/Monte & & Nativa \\
\hline Cynodon dactylon (L.) Pers. & Pastos de cerro & Cerro & CL \& BB 347 & Nativa \\
\hline $\begin{array}{l}\text { Deschampsia eminens (J. Presl) } \\
\text { Saarela var. fulva (Griseb.) Saarela }\end{array}$ & Pastos de cerro & Cerro & CL \& EF 238 & Nativa \\
\hline Deyeuxia curvula Wedd. & Pastos de cerro & Cerro & CL \& EF 264 & Nativa \\
\hline $\begin{array}{l}\text { Disakisperma dubium (Kunth) P.M. } \\
\text { Peterson \& N.W. Snow }\end{array}$ & Pastos de cerro & Cerro & CL \& BB 348 & Nativa \\
\hline Elionurus tripsacoides Humb. \& Bonpl. ex Willd. & Jaigua & Cerro & CL \& EF 242 & Nativa \\
\hline Eragrostis andicola R.E. Fr. & Pastos de cerro & Cerro & CL \& EF 236 & Nativa \\
\hline $\begin{array}{l}\text { Erioneuron avenaceum (Kunth.) Tateoka } \\
\text { var. Iongiglume (Parodi) Anton }\end{array}$ & Pastos de cerro & Cerro & CL \& EF 245 & Nativa \\
\hline Jarava ichu Ruiz \& Pav & Paja Blanca & Cerro & CL \& EF 241 & Nativa \\
\hline $\begin{array}{l}\text { Muhlembergia alopecuroides (Griseb.) } \\
\text { P.M. Peterson \& Columbus }\end{array}$ & Pastos de cerro & Cerro & CL \& BB 351 & Nativa \\
\hline Mulhenbergia ciliata (Kunth) Trin. & Pastos de cerro & Cerro & $\begin{array}{l}C L \& E F \\
233,240\end{array}$ & Nativa \\
\hline Paspalum humboldtianum Flüggé & Pastos de cerro & Cerro & $C L \& B B 350$ & Nativa \\
\hline Sporobolus phleoides Hack. & Pastos de cerro & Cerro & CL \& EF 239 & Nativa \\
\hline \multicolumn{5}{|l|}{ GERANIACEAE } \\
\hline Erodium cicutarium (L.) L'Hér. ex Aiton & Pastos de cerro & Cerro & CL 375 & Nativa \\
\hline Geranium sessiliflorum Cav. & Pastos de cerro & Cerro & & Nativa \\
\hline \multicolumn{5}{|l|}{ POLIGONACEAE } \\
\hline Coccoloba tiliacea Lindau & Álamo de campo & Monte & $\begin{array}{l}\text { CL \& HC } \\
202,217\end{array}$ & Nativa \\
\hline \multicolumn{5}{|l|}{ POLYPODIACEAE } \\
\hline Microgramma squamulosa (Kaulf.) de la Sota & $\begin{array}{l}\text { Kaleguala, } \\
\text { Calaguala }\end{array}$ & Monte & CL \& EF 285 & Nativa \\
\hline Pleopeltis macrocarpa (Bory ex. Willd.) Kaulf. & $\begin{array}{l}\text { Kaleguala, } \\
\text { Calaguala }\end{array}$ & Monte & $C L \& B B 271$ & Nativa \\
\hline \multicolumn{5}{|l|}{ ROSACEAE } \\
\hline Tetraglochin cristata (Britton) Rothm. & $\begin{array}{l}\text { Canguia, } \\
\text { Choquecanguia }\end{array}$ & Cerro & $\begin{array}{l}C L \& E F \\
162,190\end{array}$ & Nativa \\
\hline \multicolumn{5}{|l|}{ RUBIACEAE } \\
\hline Richardia brasiliensis Gomes & Pastos de cerro & Cerro & CL \& EF 231 & Nativa \\
\hline
\end{tabular}




\begin{tabular}{|c|c|c|c|c|}
\hline Familia y Especie & Nombre Local & UP & Voucher & Estatus \\
\hline \multicolumn{5}{|l|}{ SCROPHULARIACEAE } \\
\hline Buddleja tucumanensis Griseb. & San Juan Cora & Cerro & $\begin{array}{l}\text { CL \& EF } \\
220,277\end{array}$ & Nativa \\
\hline Tecoma garrocha Hieron. & Guaranguay & Cerro/Monte & CL \& HC 279 & Nativa \\
\hline \multicolumn{5}{|l|}{ SOLANACEAE } \\
\hline Lycianthes lycioides (L.) Hassl. & Chirimoye & Cerro & CL \& BB 307 & Nativa \\
\hline lochroma australe Griseb. & Sermonilla & Cerro & CL \& EF 143 & Nativa \\
\hline Solanum palitans C.V. Morton & Ñusco Blanco & Cerro & CL \& BB 314 & Nativa \\
\hline \multicolumn{5}{|l|}{ ULMACEAE } \\
\hline Celtis iguanaea (Jacq.) Sarg. & Tala & Monte & CL \& HC 201 & Nativa \\
\hline \multicolumn{5}{|l|}{ VERBENACEAE } \\
\hline Lippia turnerifolia Cham. & Pastos de cerro & Cerro & CL \& EF 235 & Nativa \\
\hline Verbena hispida Ruiz \& Pav. var. hispida & Verbena & Cerro & CL \& BB 321 & Nativa \\
\hline \multicolumn{5}{|l|}{ VIOLACEAE } \\
\hline Pombalia parviflora (Mutis ex L.f.) Paula-Souza & Pastos de cerro & Cerro & CL \& EF 232 & Nativa \\
\hline \multicolumn{5}{|l|}{ ZYGOPHYLLACEAE } \\
\hline $\begin{array}{l}\text { Porlieria microphylla (Baill.) } \\
\text { Descole, O'Donell \& Lourteig }\end{array}$ & Yapan del monte & Monte & CL \& HC 199 & Nativa \\
\hline
\end{tabular}

de etnoespecies: "pastos de monte", "pastos de cerro" y "pastos de ciénego"; mientras que la denominada "pastos que crecen en los palos" toma como referencia el soporte sobre el cual crecen las especies, ya que este grupo está integrado por herbáceas epifitas de monte.
Otras cuatro categorías aluden a la preferencia de las especies ganaderas en su consumo: "pastos oveja", "pastos vaca", "pastos cabra" y "comida de burro". Se observa una categoría específica empleada para referir a todas las etnoespecies de la familia Bromeliaceae indistintamente; y

\section{Tabla 2. Principales especies cultivadas empleadas para forraje en Iruya (Salta, Arg.).}

\begin{tabular}{|c|c|c|c|}
\hline Familia y Especie & Nombre Local & UP & Observaciones \\
\hline \multicolumn{4}{|l|}{ FABACEAE } \\
\hline Medicago sativa $\mathrm{L}$. & Alfalfa & Cerro & Introducida, perenne. Se conserva seca p/forraje. \\
\hline Vicia faba L. & Habas & Cerro & $\begin{array}{l}\text { Alimenticia, anual de verano (dic.-feb.). Las partes } \\
\text { vegetativas p/forraje. }\end{array}$ \\
\hline \multicolumn{4}{|l|}{ POACEAE } \\
\hline Avena sativa $\mathrm{L}$. & Avena & Cerro & $\begin{array}{l}\text { Introducida, anual de verano (dic.-feb.). Se conserva seca } \\
\text { p/forraje. }\end{array}$ \\
\hline Dactylis glomerata L, & Pasto ovillo & Cerro & $\begin{array}{l}\text { Introducida, perenne. Consumo directo de parte aérea } \\
\text { fresca o seca. }\end{array}$ \\
\hline Eragrostis curvula (Schrad.) Nees & Pasto llorón & Cerro & $\begin{array}{l}\text { Introducida, perenne. Consumo directo de parte aérea } \\
\text { fresca o seca. }\end{array}$ \\
\hline Hordeum vulgare $\mathrm{L}$. & Cebada & Cerro & $\begin{array}{l}\text { Introducida, anual de verano (dic.-feb.). Se conserva seca } \\
\text { p/forraje. }\end{array}$ \\
\hline Triticum spp. & Trigo & Cerro & $\begin{array}{l}\text { Alimenticia, anual de verano (dic.-feb.). Espigas y partes } \\
\text { aéreas secas p/forraje. }\end{array}$ \\
\hline Zea mays L. & Maíz. & Cerro & $\begin{array}{l}\text { Alimenticia, anual de verano (dic.-feb.). Partes vegetativas } \\
\text { y granos p/forraje. }\end{array}$ \\
\hline \multicolumn{4}{|l|}{ SOLANACEAE } \\
\hline Solanum tuberosum ssp. andigena & Papa & Cerro & $\begin{array}{l}\text { Alimenticia, anual de verano (dic.-feb.). Las partes } \\
\text { vegetativas p/forraje. }\end{array}$ \\
\hline
\end{tabular}


Tabla 3. Clasificación vernácula de los recursos forrajeros, descripción de etnocategorías.

\begin{tabular}{|c|c|c|}
\hline Etnocategoría & Descripción del grupo & Manejo principal \\
\hline Pastos de monte & $\begin{array}{l}\text { Herbáceas, principalmente } \\
\text { gramíneas de porte medio ( } 1 \\
\text { m de altura aproximadamente), } \\
\text { disponibles en la UP de } \\
\text { monte en la época seca. }\end{array}$ & $\begin{array}{l}\text { El manejo del pastoreo es directo y extensivo } \\
\text { en la UP monte. Se consideran de gran valor } \\
\text { nutritivo, especialmente en la época seca. }\end{array}$ \\
\hline Pastos de cerro & $\begin{array}{l}\text { Herbáceas, principalmente } \\
\text { gramíneas de porte bajo } \\
\text { o rastreras, disponibles } \\
\text { en la UP de cerro durante } \\
\text { la época húmeda. }\end{array}$ & $\begin{array}{l}\text { El manejo del pastoreo es directo en la UP cerro, } \\
\text { concentrando su uso en época estival porque } \\
\text { están de rebrote. Ovinos y caprinos las pastorean } \\
\text { durante todo el año, bovinos solo en verano. } \\
\text { Consideradas poco nutritivas en estado seco, por } \\
\text { lo cual se requiere suplementación forrajera. }\end{array}$ \\
\hline Pastos de Ciénego & $\begin{array}{l}\text { Herbáceas que vegetan en } \\
\text { bofedales y ciénagas de } \\
\text { las UP de cerro y valle. }\end{array}$ & $\begin{array}{l}\text { El manejo del pastoreo es directo y controlado. El } \\
\text { atributo señalado consiste en mantenerse en estado } \\
\text { vegetativo durante todas al épocas del año, por lo que } \\
\text { son consideradas una fuente de forraje muy apreciada, } \\
\text { a pesar de que pueden encontrarse en parajes de } \\
\text { difícil acceso y/o de pastoreo poco frecuente. }\end{array}$ \\
\hline $\begin{array}{l}\text { Pastos que crecen } \\
\text { en los palos }\end{array}$ & $\begin{array}{l}\text { Epífitas herbáceas } \\
\text { (Pteridophytas y Angiospermae) } \\
\text { que vegetan sobre troncos } \\
\text { y ramas de los árboles } \\
\text { en la UP de monte. }\end{array}$ & $\begin{array}{l}\text { El manejo es extensivo, son consumidas directamente por } \\
\text { el ganado bovino según la oportunidad durante el pastoreo. } \\
\text { Son consideradas un importante forraje durante todas las } \\
\text { épocas del año por estar siempre verdes y disponibles. }\end{array}$ \\
\hline Pastos oveja & $\begin{array}{l}\text { Constituyen por lo general } \\
\text { gramíneas bajas, blandas } \\
\text { y palatables presentes } \\
\text { en pastizales de las UP } \\
\text { de cerro y valle. }\end{array}$ & $\begin{array}{l}\text { El manejo es extensivo, son consumidas directamente } \\
\text { durante el pastoreo. Se refiere al conjunto de } \\
\text { especies preferidas por el ganado ovino. }\end{array}$ \\
\hline Pastos vaca & $\begin{array}{l}\text { Conjunto de especies de } \\
\text { diverso porte que puede incluir } \\
\text { elementos de los otros grupos } \\
\text { y de las UP de cerro, valle } \\
\text { y monte indistintamente. }\end{array}$ & $\begin{array}{l}\text { Se trata de las etnoespecies que son más palatables } \\
\text { para los bovinos. Pueden ser manejados con pastoreo } \\
\text { directo o bien, cosechados para suplementar en } \\
\text { el corral; ya que algunas etnoespecies crecen } \\
\text { en lugares inaccesibles para los animales. }\end{array}$ \\
\hline Comida de burro & $\begin{array}{l}\text { Conjunto de porte arbustivo, } \\
\text { su caracteristica principal } \\
\text { es que son aromáticas, o } \\
\text { resinosas y duras, por lo } \\
\text { que no son consumidas } \\
\text { por otro tipo de ganado. }\end{array}$ & $\begin{array}{l}\text { Son los forrajes percibidos como de peor calidad, } \\
\text { con baja calidad nutricional, de menor preferencia } \\
\text { para las otras especies de ganado excepto los } \\
\text { asnos. Se trata de una categoría utilizada de manera } \\
\text { despectiva al referirse a los forrajes que no poseen } \\
\text { preferencia por los otros tipos de ganado. }\end{array}$ \\
\hline Pastos cabra & $\begin{array}{l}\text { Conjunto de especies preferidas } \\
\text { por los caprinos, entre ellas } \\
\text { predominan las arbustivas. }\end{array}$ & $\begin{array}{l}\text { Pueden incluir elementos de los otros grupos, como } \\
\text { también de las UP de cerro, valle y monte. }\end{array}$ \\
\hline Taracas & $\begin{array}{l}\text { Este concepto refiere a la parte } \\
\text { vegetativa de las especies } \\
\text { de la familia Bromeliaceae, } \\
\text { especialmente requeridas } \\
\text { como forraje de emergencia } \\
\text { en los períodos de escasez. }\end{array}$ & $\begin{array}{l}\text { Es un forraje de difícil obtención debido a los sitios } \\
\text { inaccesibles donde crecen las especies. Por ejemplo } \\
\text { se denomina "taraca de yaquispala" a la parte de hojas } \\
\text { arrosetadas de la "yaquispala" (Puya yaquespala), } \\
\text { constituye un forraje de zonas altas y filos en UP de } \\
\text { cerro, siendo muy preciado para alimentar bovinos. }\end{array}$ \\
\hline Pastos fuertes & $\begin{array}{l}\text { Es un concepto transversal } \\
\text { aplicable a todos los vegetales } \\
\text { que se emplean como forraje. }\end{array}$ & $\begin{array}{l}\text { Refiere a los forrajes percibidos como de mayor } \\
\text { calidad nutricional, por su buena capacidad para } \\
\text { alimentar al ganado respecto a otros forrajes. }\end{array}$ \\
\hline
\end{tabular}

otra categoría transversal, centrada en la calidad nutricional de los vegetales denominada "pastos fuertes" que es utilizada para aquellas etnoespecies percibidas como de mayor calidad nutricional, cuya capacidad de alimentar al ganado es mayor respecto a las otras. 


\section{Califano, L. M. - Manejo de especies forrajeras en Iruya (Salta, Argentina)}

Esta clasificación permite que las categorías sean empleadas de manera superpuesta, es decir, así como refieren al sitio donde crecen también puede aludir a la calidad nutricional o a la preferencia de consumo: por ejemplo, un "pasto que crece en los palos" también puede ser considerado "pastos vaca" por ser preferencia de consumo de los bovinos, o ser simultáneamente un "pasto fuerte" por la percepción respecto su capacidad nutritiva.

\section{Estrategias y prácticas de manejo de los recursos forrajeros}

En los períodos de escasez de forraje las UD deben evitar la pérdida de peso de los animales, para lo cual se provee de forrajes adicionales a fin de suplementar el pastoreo directo en los ambientes naturales. El forraje adicional puede porvenir de diferentes fuentes que están disponibles a lo largo del ciclo anual pastoril: reservas de vegetación nativa (praderas y pastizales conservados intactos en cerramientos), forrajes cultivados especialmente y restos de cultivos. En la Tabla 4 se presenta el esquema del calendario de disponibilidad forrajera anual según su tipo de fuente.

El $83 \%$ de los productores consultados posee como estrategia principal de manejo el pastoreo en praderas naturales, que consiste en una rotación entre parajes de pastoreo dentro del mismo ambiente, cerro o monte, que se complementa con el sistema de ganadería trashumante que otorga movilidad vertical entre estos ambientes. Mientras que el $17 \%$ recurre a una estrategia complementaria de suplementación con forrajes cultivados: en primer lugar, con maíz (Zea mays L.), seguido de cebada (Hordeum vulgare L.) y alfalfa (Medicago sativa L.). El 12\% declara tener una reserva de forraje nativo, esta estrategia hace referencia al cuidado de sectores de pastoreo donde se encuentra principalmente "sevenguilla" [Cortaderia hieronymi (Kuntze) N.P.Barker \& H.P.Linder] como recurso forrajero principal. Esta práctica se realiza manteniendo intactos estos sectores a partir de su cerramiento perimetral con muros de piedra o "pircas", ladrillos de barro o "adobes" y alambrados. Cuando se presenta la emergencia forrajera los animales ingresan al cerramiento a pastorear; también se cosechan estas especies forrajeras para ser entregadas en los corrales. Este tipo de reserva forrajera se realiza principalmente para la alimentación de la etnocategoría "punistas", por ser los animales más expuestos a la escasez de forraje en el período invernal. La estrategia forrajera con más baja aplicación es la suplementación con rastrojos de cultivos.

La suplementación a partir del cultivo de forrajes es una práctica difundida en las UP de cerro y de valle, por ser la posibilidad más accesible y concreta. Como en Iruya, el crecimiento de los cultivos es estacional por las condiciones climáticas, está concentrado en los meses de primavera y verano; por ello dentro del ciclo anual coinciden el cultivo de especies forrajeras con aquellos cultivos dedicados a la alimentación de la UD. Los forrajes cultivados se siembran entre los meses de noviembre a diciembre, sujetos a las lluvias ya que son sembrados a secano. El almacenamiento del forraje es la forma más difundida de conservación para uso diferido en los períodos de escasez; las condiciones ambientales permiten el secado natural del forraje al sol y viento (cortado o en pie); dentro de la parcela o cosechado y almacenado en parvas.

En la Tabla 2 se detallan los forrajes cultivados, entre los cuales se encuentra las forrajeras anuales como la avena (Avena sativa L.), el trigo (Triticum spp.) y la cebada en sus dos variedades, alimenticia y forrajera (Hordeum vulgare); entre los cultivos perennes el más difundido es la alfalfa (Medicago sativa) y el pasto llorón [Eragrostis curvula

Tabla 4. Esquema del calendario anual forrajero en sistemas ganaderos de Iruya (Salta, Arg.).

\begin{tabular}{|c|c|c|c|c|c|c|c|c|c|c|c|c|}
\hline \multirow{2}{*}{ Fuente Forrajera } & \multicolumn{6}{|c|}{ Meses época seca } & \multicolumn{6}{|c|}{ Meses época húmeda } \\
\hline & M & $\mathbf{J}$ & J & $\mathbf{A}$ & $\mathbf{S}$ & $\mathbf{0}$ & $\mathbf{N}$ & D & $\mathbf{E}$ & $\mathbf{F}$ & M & $\mathbf{A}$ \\
\hline Praderas naturales & & & & & & & & & & & & \\
\hline Forrajes cultivados & & & & & & & & & & & & \\
\hline Restos de cultivos & & & & & & & & & & & & \\
\hline
\end{tabular}


(Schrad.) Nees], en algunos casos el pasto ovillo (Dactylis glomerata L.) (Fig. 3). El pasto llorón y el pasto ovillo se han incorporado desde hace unas décadas por su promoción desde dependencias estatales a través de proyectos para fomentar la mejora en la ganadería local.

La estrategia de trashumancia es básicamente un manejo ganadero extensivo que involucra la gestión de superficies de tierra relativamente grandes por cabeza, con un nivel muy bajo de mano de obra. Estas amplias superficies no cuentan con alambrado perimetral, los animales se mueven libremente dentro de un rango de superficie, buscando los forrajes de mayor palatabilidad en primer término. Mientras realizan este tipo de pastoreo, los animales son controlados periódicamente para evitar que se alejen del sitio de pastoreo separándose del resto del rodeo. La inexistencia de alambrados perimetrales facilita el desplazamiento de los animales durante el pastoreo y evita su confinamiento; por ello la trashumancia se acompaña de prácticas de manejo de menor escala como rotaciones entre parajes dentro del mismo ambiente y la quema de pastos para fomentar el rebrote. La quema posee la finalidad de estimular el rebrote de matas y limpiar el exceso de materia seca, para disminuir la presencia de parásitos externos en los sitios de pastoreo que luego atacan a los animales; esta práctica se realiza únicamente en la UP de cerro por no poseer árboles. La quema se realiza en los parajes de pastoreo entre los cuales se rota el ganado, se aplica a los sectores que son percibidos
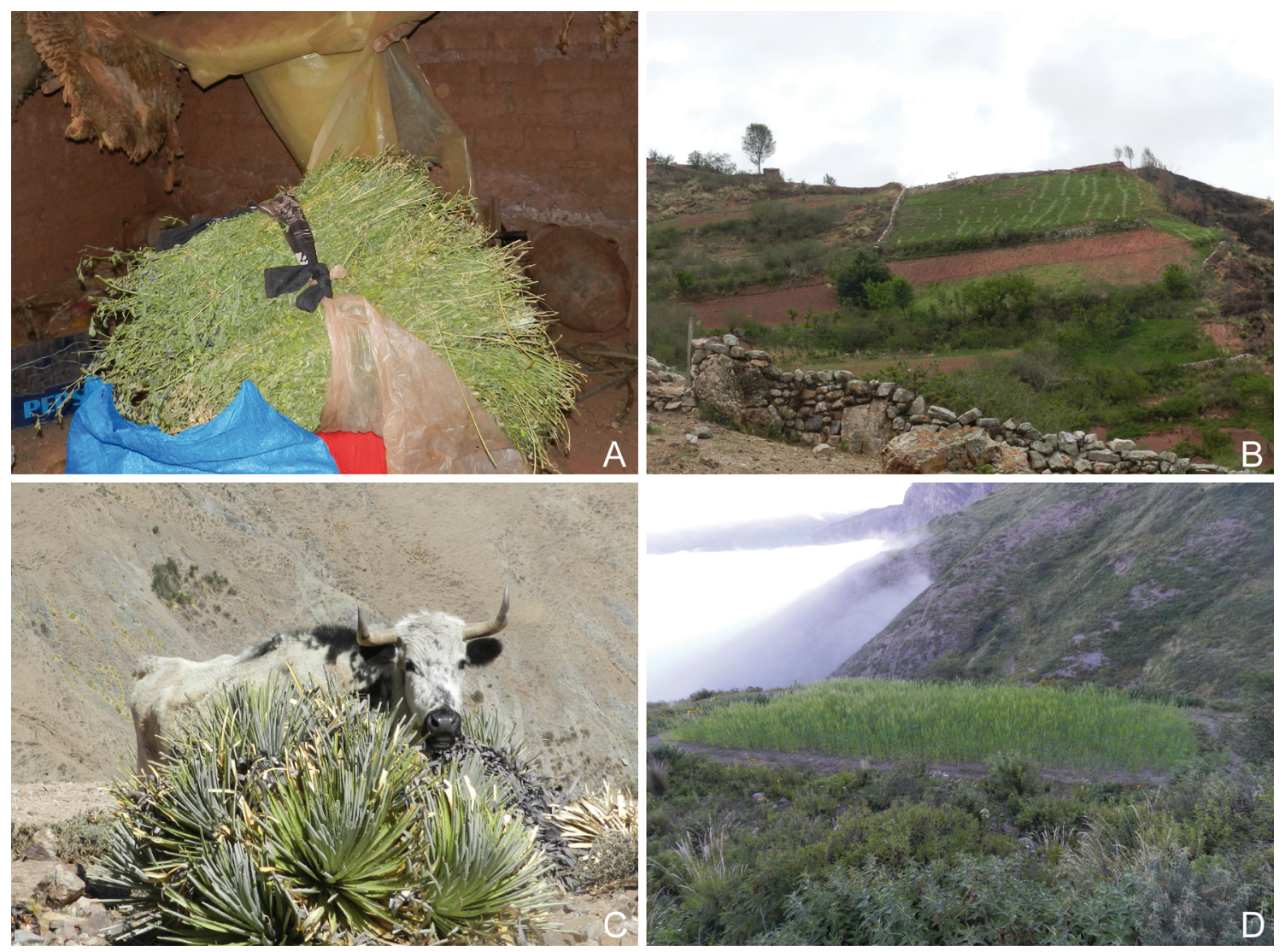

Fig. 3. A: Forraje cultivado almacenado, alfalfa (Medicago sativa) para suplementación forrajera en el corral dentro de la UP de "cerro". B: Parcela de alfalfa (Medicago sativa) cortada en hileras para su secado y almacenamiento en la UP de "cerro". C: Bovino consumiendo "taraca de yaquispala" (Puya yakespala), forraje silvestre de zonas altas y filos en UP de "cerro". D: Parcela estival de forraje cultivado, cebada (Hordeum vulgare) en la UP de "cerro". 


\section{Califano, L. M. - Manejo de especies forrajeras en Iruya (Salta, Argentina)}

como de mayor concentración de matas secas, también consiste en una práctica sanitaria de control de parásitos externos. Las quemas se concentran a partir de la festividad de San Juan Bautista el 24 de junio, ya que forman parte de los rituales en conmemoración del santo patrono del ganado ovino; y se prolongan todo el mes de julio. La noche previa a la festividad de San Juan se realizan quemas simbólicas de matas de pastos secos denominadas "luminarias de San Juan", este momento del año coincide con la época de mayor frío y días más cortos. Se considera que con esta fiesta se inicia un período de gran sequedad, fuertes heladas y vientos, con significativa escasez de forraje, características del periodo invernal. Para realizar las quemas no existe mayor tecnología que el conocimiento del productor respecto al clima y la velocidad del viento que avivará el fuego; como cortafuegos naturales se emplean particularidades del relieve: afloramientos rocosos, peñascos, gargantas o quebradas, ríos, barrancas.

\section{Gestión de los recursos forrajeros en la comunidad}

La confluencia con la modernidad y sus patrones de manejo de la tierra produjo modificaciones en los principios que regían la vida comunal andina (Van Kessel, 2000). Actualmente el concepto de vida en comunidad se muestra diverso y es particular para cada comunidad, constituye una mixtura entre formas prehispánicas de uso de las tierras comunales, modelos de manejo colonial y conceptos modernos de manejo empresarial acordes a la propiedad privada.

En el patrón de vida comunitario local los animales se individualizan claramente como propiedad privada de una UD o de un productor individual, posesión que es otorgada a través del ritual de "señalada o marcada". En este ritual se identifican las crías producidas durante el ciclo; en el caso de los rumiantes menores se les realiza la señal mediante un corte en las orejas para el registro del propietario; en la hacienda bovina se realiza la marca con el símbolo del propietario con un hierro caliente sobre el lomo o en una de las ancas del animal. Tanto la marca como la señal se registran en el libro provincial de marcas y señales donde se identifica y vincula al propietario con sus animales. De esta forma se cumple con la formalidad exigida por el Estado en registrar la hacienda; pero simultáneamente, de manera tradicional, se adorna e identifica a los animales con accesorios de lanas de colores cosidos en las orejas denominados "chumpis" o "flores". Así conviven dos formas de identificación de los animales: la establecida por los canales formales estatales (marca y señal a fuego) y la realizada de forma tradicional con lanas de colores en las orejas.

A través de la organización comunitaria se establecen un conjunto de normas para el uso de los espacios comunes, cuyo objeto es el control social por parte de los propios usuarios y de la comunidad. El manejo del ganado bovino implica el acuerdo con la comunidad para el uso de espacios comunitarios conjuntamente con aquellos de uso privado en los diferentes momentos del ciclo anual. Los acuerdos son realizados de manera verbal en las asambleas mensuales de la organización comunitaria, siempre bajo la consulta y permiso de los integrantes, aunque también pueden quedar escritos en las actas de la organización cuando se registran cambios, o se presentan conflictos. Como las comunidades constituyen organizaciones locales tradicionales en las cuales los lazos de parentesco son fuertes, sus integrantes pueden pertenecer a unas pocas familias con alta probabilidad de estar emparentadas. Este aspecto es importante en referencia al cumplimiento de las obligaciones y al respeto de los derechos contraídos.

Cada propietario de ganado bovino posee el derecho de uso sobre parajes donde se encuentran los sitios de pastoreo (llamados localmente "paraderos"), tanto en el monte como en el cerro. El derecho de uso en estos parajes ha sido obtenido a través de herencia familiar, por arreglo con otro productor que no está haciendo uso pleno del mismo o a través de acuerdos comunitarios. La cantidad de derechos de pastajes que contrae un ganadero de una comunidad depende de la cantidad de bovinos y de cuantos sitios o parajes de pastoreo emplea en el ciclo anual: desde dos sitios de pastaje, uno en el cerro y uno en el monte, a más de dos por ambiente que llevan a contraer obligaciones con otras comunidades. En el caso de pertenecer a una comunidad que dentro de su territorio no posee el ambiente de monte, los productores requieren acordar con otra comunidad los derechos de pastoreo para mantener la estrategia de la trashumancia. Las obligaciones de pastoreo son las retribuciones que debe realizar el ganadero a la comunidad por el derecho al uso de los espacios comunitarios; pueden implicar un pago en dinero, consistente en una cuota anual al Consejo Comunitario o bien la 
devolución en jornales para tareas comunitarias como: mantenimiento y arreglo de caminos, de canales, de albañilería, etc. El uso de un paraje de pastoreo da derecho a la plena utilización de ese espacio territorial por parte del propietario de ganado, es decir que, además de los recursos forrajeros puede utilizar las fuentes de agua y otros recursos naturales como: leña, maderas, frutos, especias, animales de caza, etc.; como también disponer la construcción de la infraestructura que necesite. Dentro de los territorios comunitarios la UD puede tener un promedio de 3 a 5 hectáreas de uso individual donde se encuentran potreros y corrales, donde se realiza la siembra de pasturas y de los cultivos.

La etnocategoría ganadera que posee la UD representa una diferencia al momento de gestionar los sitios de pastoreo frente a la comunidad, existe una relación entre la gestión y las etnocategorías presentadas en los apartados anteriores. La misma se visibiliza al momento de planificar el pastoreo por parte de la UD, ya que si es propietaria únicamente de vacas "punistas" no requerirá acuerdos para el uso de parajes de pastoreo en el ambiente de monte, por lo cual no contraerá obligaciones con la comunidad por el acceso a los recursos forrajeros de ese espacio ambiental ya que no implementa la trashumancia como práctica. En tales casos la suplementación forrajera estará circunscripta a las posibilidades que ofrece el ambiente de cerro, es decir cerramientos y pasturas cultivadas principalmente de forma privada. Por el contrario, si la UD posee animales de la etnocategoría "monteñas", esto representa una ventaja para acceder a sitios de pastoreo localizados en el espacio ambiental del monte, lo que permite a la UD la implementación de la trashumancia como principal estrategia forrajera para acceder a las etnocategorías forrajeras propias de esa unidad ambiental.

\section{Discusión y Conclusiones}

La perspectiva "emic" se refiere al conjunto de prácticas, conocimientos y creencias que surgen del accionar individual o social, y permiten visualizar como los seres humanos establecen su relación con su entorno ambiental (Toledo, 2002). El análisis del sistema ganadero tradicional en Iruya a partir de la perspectiva emic permite comprender que las relaciones entre humanos y plantas, se encuentran mediadas por la ganadería como práctica productiva central.

Las clasificaciones vernáculas identificadas permiten observar que los campesinos ordenan los recursos forrajeros y el ganado en grupos que se le presentan como porciones de realidad biológica de características similares. Como resultado las etnotaxas se ven relacionadas según su funcionalidad a las preferencias de uso, a la elección local, a las posibilidades reales de acceso y/o de mano de obra, o también pueden estar sujetas a la influencia mercantil, entre otros aspectos (Sánchez et al., 2007; Rosales Bustamante et al., 2009; Lambaré \& Pochettino, 2012). Se reconocen en Iruya dos sistemas de clasificación local "folk" estructurados en base a categorías empíricas de uso y manejo de animales y de los vegetales; uno está referido a los recursos forrajeros con diez etnocategorías; y otro al ganado bovino con dos etnocategorías de manejo.

Una clasificación local "vernacular" de los vegetales construida en base a la percepción de atributos comunes, fue referida en por Aldunate et al. $(1981,1983)$ en comunidades Andinas del $\mathrm{N}$ de Chile. Estos autores distinguen del total de etnoespecies aquellas reconocidas con una denominación propia exclusiva a una sola etnoespecie, de las denominaciones colectivas que aluden a grupos de etnotaxas. Aspecto se muestra semejante con los criterios utilizados por los campesinos de Iruya para la identificación de las etnocategorías en tres ejes: a) aquellos términos que aluden a la similitud en la fisonomía de las especies que integran un grupo, b) los términos que señalan la UP donde se encuentra a ese grupo o c) o los que se refieren a la preferencia de consumo o calidad nutricional de sus componentes. $\mathrm{Su}$ característica particular es que no son denominaciones mutuamente excluyentes ya que pueden ser empleadas simultáneamente entre sí.

La riqueza en etnoespecies forrajeras relevada está dentro de los rangos planteados por otras investigaciones etnobotánicas de ambientes similares cercanos; por ejemplo para la puna de la provincia de Jujuy, Quiroga Mendiola (2011) menciona una riqueza de 91 especies forrajeras, en la zona de precordillerana y la puna del norte de Chile Aldunate et al. (1981) mencionan 83 etnotaxas con uso forrajero, mientras que para la 


\section{Califano, L. M. - Manejo de especies forrajeras en Iruya (Salta, Argentina)}

misma región Villagrán \& Castro (1997) recopilan 72 nombres vernáculos vinculados a la flora local.

En este artículo se amplió la información sobre los usos y las prácticas de manejo de los recursos vegetales que conforman el sistema de gestión propio de la ganadería tradicional de Iruya. Se determinaron 81 especies, entre silvestres y cultivadas; y dos sistemas de clasificación vernáculos con etnocategorías de uso: uno para el manejo ganadero con dos categorías de bovinos -que fue señalado anteriormente por Lahitte \& Hurrell (1994)- y otro para el manejo de los recursos forrajeros con diez etnocategorías. Se identificaron estrategias de manejo que permiten la continuidad de la alimentación del ganado garantizando la provisión de forraje adicional para la suplementación durante el ciclo anual, realizados por el $17 \%$ de los productores. Se destaca la trashumancia como la estrategia que integra todas las prácticas de manejo en el movimiento vertical entre diferentes UP, y que es realizado por $83 \%$ de los productores.

La producción campesina de Iruya presenta un sistema ganadero de crianza de animales extensivo y diversificado con diferentes especies ganaderas que se localizan en distintos ambientes, y se mueven entre ellos, lo que permite sostener la subsistencia de las UD. La cría de bovinos de la etnocategoría "monteñas" utiliza la estrategia de trashumancia como principal práctica de manejo forrajero; mientras que el ganado menor y la cría de bovinos de la categoría "punistas" son manejadas con rotaciones entre parajes de pastoreo solo dentro del ambiente de cerro. Las etnocategorías forrajeras se relacionan con las ganaderas por su disponibilidad en los ambientes de "cerro" y "monte", como también por su valor como alimento y suplemento forrajero en períodos de escasez. Se visualiza un manejo ganadero, con diferentes estrategias y con arreglo dentro del ciclo anual, donde hay complementariedad de uso de los recursos forrajeros de las UP y con las categorías ganaderas respectivamente, lo que otorga a estos sistemas la posibilidad de realizar ganadería bovina.

Como sistema ganadero de subsistencia su finalidad es garantizar la reproducción del siguiente ciclo, a partir de la aplicación de prácticas de manejo construidas desde su conocimiento local, casi independientes de contextos externos al territorio, pero muy dependientes de las características ambientales que presenta cada ambiente y cada etapa del ciclo anual. Se observa una producción ganadera de base pastoril cuyos medios de producción principales son la tierra y los recursos naturales presentes que, por medio de la aplicación de trabajo directo, creatividad, conocimiento local y un saber hacer específico e histórico, realiza la reproducción de los medios de vida tal lo plantea Paz et al. (2018). El estudio de las diferentes formas de uso y manejo de los recursos vegetales tiene un alto valor teórico y práctico; documentar la experiencia tecnológica acumulada por los seres humanos para interactuar con las plantas, pone de manifiesto las estrategias de gestión que contribuyen entre otros objetivos al desarrollo sostenible (Blancas et al., 2010) y a la conservación de la biodiversidad (Lagos-Witte et al., 2011).

En este trabajo se brinda un aporte a la identificación de las especies forrajeras utilizadas en Iruya, los sistemas de clasificación "vernáculos" $\mathrm{y}$ a las prácticas de manejo ganadero y de recursos forrajeros desarrolladas; pero no posee el ánimo de evaluar la efectividad de las mismas. Sin duda, estos aportes requieren ser complementados con un análisis de la sustentabilidad ambiental de este sistema ganadero, como herramienta necesaria para evaluar el impacto de las prácticas de manejo en los índices productivos y medioambientales. Finalmente se señala como necesario evaluar a futuro el estado de conservación de los pastizales naturales y las pasturas implantadas empleadas en estos sistemas.

\section{Contribución de los Autores}

La autora ha realizado el diseño del trabajo, la interpretación de datos y redacción del manuscrito. El trabajo de campo se realizó con el asesoramiento del director de Tesis de doctorado.

\section{Agradecimientos}

A las comunidades y pobladores de Iruya por su permiso para realizar la investigación, por su hospitalidad y predisposición durante el desarrollo del trabajo. A P. Arenas por la dirección del trabajo de tesis de doctorado. Al Instituto Nacional de Tecnología Agropecuaria, Estación Experimental 
Abra Pampa, por la financiación a través de PRET SALJU - 1232205 con el apoyo logístico de la AER Humahuaca. A F. Echazú, B. Bartl, C. Herrera, A. Geronazzo y D. Vargas por su compañerismo y cooperación en las diferentes etapas de la investigación.

\section{Bibliografía}

ALDUNATE, C., J. ARMESTO, V. CASTRO \& C. VILLAGRÁN. 1981. Estudio etnobotánico en una comunidad precordillerana de Antofagasta: Toconce. Boletín del Museo Nacional de Historia Natural 38: 183-223. http://publicaciones.mnhn.gob.cl/668/ articles-64174_archivo_01.pdf.

ALDUNATE, C., C. VILLAGRÁN, J. ARMESTO \& V. CASTRO. 1983. Ethnobotany of pre-altiplanic community in the Andes of northern Chile. Economic Botany 37: 120-135. https://doi.org/10.1007/BF02859312.

ARCHETTI, E. P. \& K. A. STÖLEN. 1975. Explotación familiar y acumulación de capital en el campo argentino. Serie: Sociología y Política. Ed. Siglo Veintiuno. Buenos Aires, Argentina.

ARENAS, P. \& G. J. MARTÍNEZ. 2012. Estudio etnobotánico en regiones áridas y semiáridas de Argentina y zonas limítrofes. En: ARENAS, P. (ed.), Etnobotánica en regiones áridas y semiáridas del Cono Sur de Sudamérica, pp. 11-43. Edición del CEFYBO-CONICET. Buenos Aires, Argentina.

BAPTISTA LUCIO, M. P., C. F. COLLADO \& R. H. SAMPIERI. 2006. Metodología de la Investigación. Ed. McGraw-Hill Interamericana. México.

BARTL, B. 2019. "La yaquispala": prácticas locales, memoria y conservación. Boletín de la Sociedad Argentina de Botánica 54: 451-471. https://doi.org/10.31055/1851.2372.v54.n3.25369.

BENDINI, M., P. TSAKOUMAGKOS \& B. DESTEFANO. 1994. El trabajo trashumante. En: Universidad Nacional del Comahue. Grupo de Estudios Sociales Agrarios (ed.), Campesinado y ganadería trashumante en Neuquén, pp. 1-78. Ed. La Colmena. Buenos Aires, Argentina.

BENDINI, M., P. TSAKOUMAGKOS \& C. NOGUES. 2004. Los crianceros trashumantes del Neuquén. En BENDINI, M. \& C. ALEMANY (comp.), Crianceros y chacareros en la Patagonia, pp. 2340. Ed. Colmena (Cuadernos GESA, 5-INTANCRCRD). Buenos Aires, Argentina.
BIANCHI,A. R. \& C.E. YÁNEZ. 1992. Las precipitaciones del Noroeste Argentino. Ed. INTA Salta, Argentina.

BLANCAS, J, A. CASAS, S. RANGEL-LANDA, A. MORENO-CALLES, I. TORRES, E. PÉREZNEGRÓN, L. SOLIS, A. DELGADO-LEMUS, F. PARRA, Y. ARELLANES, J. CABALLERO, L. CORTEZ, R. LIRA, \& P. DAVILA. 2010. Plant management in the Tehuacán-Cuicatlán Valley, Mexico. Economic Botany 64: 287-302. https://doi.org/10.1007/s12231-010-9133-0

BOCCO DE ABEYÁ, A. 1988. Contribución al Conocimiento del Espacio Social Pastoral de Subsistencia. Cuadernos de Antropología Social 1: 79-95.

BRAUN WILKE, R. H. 1991. Plantas de interés ganadero de Jujuy y Salta Noroeste Argentino. Ed. Junta Nacional de Carnes, p. 309, Bs. As.

BRAUN WILKE, R. H.; L. P. PICCHETTI \& B.S VILLAFAÑE. 1999. Pasturas montanas de Jujuy. Ed. Gofica p. 79. Salta, Arg.

CABRERA, A. L. 1976. Regiones Fitogeográficas Argentinas. Enciclopedia Argentina de agricultura y jardinería. Ed. Acme. Buenos Aires, Argentina.

CABRERA, A. L. \& A. WILLINK. 1980. Biogeografia de América Latina. $2^{\mathrm{a}}$ edición corregida. Monografía 13. Serie de Biología. Secretaría General de la Organización de los Estados Americanos. Washington DC. EEUU.

CÁCERES, D. 2003. El campesinado contemporáneo. En: THORNTON, R. \& G. CIMADEVILLA (ed.), La extensión rural en debate: Concepciones, retrospectivas, cambios y estrategias para el Mercosur (No. C20/2), pp. 173-197. Instituto Nacional de Tecnología Agropecuaria, Buenos Aires, Argentina.

CALIFANO, L. M. 2020. Percepción y manejo del paisaje y de los recursos vegetales por campesinos trashumantes de Iruya (Salta, Argentina). Bonplandia 29: 101-118. https://doi.org/10.30972/bon.2914112.

CALIFANO, L. M. 2019. Conocimiento tradicional y manejo de los recursos vegetales en productores campesinos trashumantes de ganado bovino en Iruya (Salta, Argentina). Tesis Doctoral Facultad de Ciencias Agrarias, Universidad Nacional del Nordeste. Corrientes, Argentina.

CALIFANO, L. M. \& F. ECHAZÚ. 2013. Etnobotánica en comunidades pastoriles. Conocimiento tradicional sobre especies tóxicas para el ganado en la cuenca del río Iruya (Salta, Argentina). Bol. Soc. Argent. Bot. 48: 365-375. https://doi.org/10.31055/1851.2372.v48.n2.6271. 


\section{Califano, L. M. - Manejo de especies forrajeras en Iruya (Salta, Argentina)}

DOMPTAIL, S., \& M. H. EASDALE. 2013. Managing socio-ecological systems to achieve sustainability: A study of resilience and robustness. Environmental Policy and Governance 23: 30-45.

https://doi.org/10.1002/eet.1604.

ECHAZÚ, F., L. M. CALIFANO \& C. HERRERA. 2016. La ganadería bovina en sistemas campesinos de las comunidades de Iruya (Salta) - Abordaje de saberes, conocimientos y relevancia local. Pre Congreso ALASRU (Asociación Latinoamericana de Sociología Rural). Santiago del Estero, Argentina.

ECHAZU, F., L. M. CALIFANO, R. PAZ. \& C. HERRERA. 2013. Estrategias de la ganadería campesina en Iruya (Salta - Argentina). VII Jornadas Interdisciplinarias de Estudios Agrarios y Agroindustriales. Actas en CD-ROM ISSN 18513794. Universidad de Buenos Aires, Argentina.

ESCOLAR, D. 1996. Prácticas espacio-temporales, poder e identidad entre los baqueanos de los Andes Sanjuaninos. Cuadernos del Instituto Nacional de Antropología y Pensamiento Latinoamericano 17: 17-39.

GALAFASSI, G. P. 1994. Manejo y apropiación del medio natural por una comunidad de pastores de altura (Laguna Blanca-Catamarca). Ruralia 5: 7-25.

GÖBEL, B. 2001. El ciclo anual de la producción pastoril en Huancar (Jujuy, Argentina). En: MENGONI GOÑALONS, G., D. OLIVERA \& H. YACOBACCIO (ed.), El uso de los camélidos a través del tiempo, pp. 91-115. Ed. El Tridente, Buenos Aires.

GÖBEL, B. 2002. La arquitectura del pastoreo: Uso del espacio y sistema de asentamientos en la Puna de Atacama. Estudios Atacameños 23: 53-76. https://doi.org/10.4067/S0718-10432002002300005.

GRECO, M. G. 1995. Iruya: migración temporaria y reproducción campesina. Boletín de estudios geográficos 25: 733-740.

HILGERT, N. I. 1998. Las plantas vinculadas con el ámbito doméstico y la subsistencia de los campesinos de la cuenca del río Zenta, Dpto. Orán, Prov. Salta Tesis Doctoral. Universidad Nacional de Córdoba, Argentina.

HILGERT, N. I. 1999. Las plantas comestibles en un sector de las Yungas meridionales (Argentina). Anales del Jardín Botánico de Madrid 57: 117138.

HILGERT, N. I. 2001. Plants used in home medicine in the Zenta river basin, Northwest Argentina. J. Ethnopharmacol. 76: 11-34. https://doi.org/10.1016/S0378-8741(01)00190-8.
HILGERT, N. I. 2004. Las plantas en las festividades religiosas de la selva andina argentina. Société Suisse des Américanistes 68: 37-49.

HILGERT, N. I. 2007a. La vinculación del hombre actual con los recursos naturales y el uso de la tierra. En BROWN, A. D., M. G. MORITÁN, B. VENTURA, N. HILGERT \& L. MALIZIA (eds.), Finca San Andrés: un espacio de cambios ambientales y sociales en el Alto Bermejo, pp. 159-186. Ed. del Subtrópico, Fundación ProYungas, Tucumán, Argentina.

HILGERT, N. I. 2007b. Plantas silvestres, ámbito doméstico y subsistencia. En Finca San Andrés. En BROWN, A. D., M. G. MORITÁN, B. VENTURA, N. I. HILGERT \& L. MALIZIA (eds.), Finca San Andrés: un espacio de cambios ambientales y sociales en el Alto Bermejo, pp. 187-228. Ed. del Subtrópico, Fundación ProYungas, Tucumán, Argentina.

HOCSMAN, L. D. 2011. Estrategias territoriales, re-campesinización y etnicidad en los Andes de Argentina. Ed.Consejo Latinoamericano de Ciencias Sociales - CLACSO. http:// biblioteca.clacso.edu. ar/ar/libros/coedicion/ EstrategiasTerritoriales.pdf

IBODA. 2019. Instituto de Botánica Darwinion. Flora del Cono Sur Catálogo de Plantas Vasculares [online]. Disponible: http://www2.darwin.edu.ar/ Proyectos/ FloraArgentina (Consulta 10/19).

INDEC. 2010. Instituto Nacional de Estadística y Censos. Censos Nacionales de Población, Hogares y Viviendas 2001, 2010 [online]. Disponible: http:// www. indec.gov.ar (Consulta 10/2019).

JIMÉNEZ-ESCOBAR, N. D. \& G. J. MARTÍNEZ. 2019. Plantas que mantienen al ganado: conocimiento campesino asociado a especies forrajeras en la Sierra de Ancasti (Catamarca, Argentina). Bol. Soc. Argent. Bot. 54: 617-635. https://doi. org/10.31055/1851.2372.v54.n4.24707.

LAGOS-WITTE, S., O. L SANABRIA DIAGO, P. CHACÓN \& R. GARCÍA. (2011). Manual de herramientas etnobotánicas relativas a la conservación y el uso sostenible de los recursos vegetales. Red Latinoamericana de Botánica [online]. http://www.ibiologia.unam.mx/gela/ manualetnobot.pdf.

LAHITTE, H. \& J. HURRELL. 1994. Modelos etnobotánicos en etnomedicina. Reflexiones en ecología biocultural sobre la base de un estudio en el Noroeste de la Argentina. Estudios de la división etnografía, FCN y Museo UNLP. Año $7 \mathrm{n}^{\circ} 1$. 
LAMBARÉ, A. \& M. L. POCHETTINO. 2012. Diversidad local y prácticas agrícolas asociadas al cultivo tradicional de duraznos, Prunus persica (Rosaceae), en el noroeste de Argentina. Darwiniana 50: 174-186. https://doi.org/10.14522/darwiniana.2014.502.448.

LEMA, V. \& M. L. POCHETTINO. 2012. Cambio y continuidad al plato: los saberes culinarios y su rol en la dinámica de la diversidad biocultural. En: BABOT, M. P., M. MARSCHOFF \& F. PAZZARELLI (eds.), Las manos en la masa: arqueologías, antropologías e historias de la alimentación en Suramérica, Ed. Universidad Nacional de Córdoba, Córdoba, pp. 25-46.

LEVY HYNES, A. 1994. Uso de las plantas por las comunidades campesinas de las Yungas del extremo norte de Argentina. Facultad de Ciencias Naturales e Instituto Miguel Lillo, Universidad Nacional de Tucumán, Curso de entrenamiento de la Carrera de Ciencias Biológicas. Ed. LIEY, FCN e IML, Universidad Nacional de Tucumán, Argentina.

MADRAZO, G. B. 1981. Comercio interétnico y trueque recíproco equilibrado intraétnico: su vigencia en la puna argentina y áreas próximas, desde la independencia nacional hasta mediados del siglo XX. Desarrollo Económico 21: 213-230. https://doi.org/10.2307/3466541.

MAFFIA, M. M. \& B. ZUBRZYCKI. 1999. Parentesco $y$ organización familiar en una comunidad rural del valle de Hualfin, Catamarca. Ponencia presentada en III RAM, Reunión de Antropología del MERCOSUR. Departamento de Antropología Social de la Universidad Nacional de Misiones, Posadas, Argentina.

MARTÍNEZ, M. 2006. La investigación cualitativa (Síntesis conceptual). Revista de Investigación en Psicología 9: 123-146. https://doi.org/10.15381/rinvp.v9i1.4033.

MERLINO, R. \& M. RABEY. 1983. Pastores del altiplano andino meridional: Religiosidad, territorio y equilibrio ecológico. Allpanchis 21: 149-171.

MERLINO, R. \& M. SANCHEZ PROAÑO. 1996. Transformaciones sociales y cambios en el sistema de manejo ganadero entre las poblaciones Puneñas. Zooarqueología de Camélidos, perspectivas teóricas y metodológicas, vol. 2, p. 47-65.

MUIÑO, W. A. 2010. Ethnobotanical study of the rural population of the West of the Pampa Plain (Argentina). Ethnobotany Research \& Applications 8: 219-231.

https://doi.org/10.17348/era.8.0.219-231.
MURRA, J. V. 1975. El control vertical de un Máximo de Pisos Ecológicos en la Economía de las Sociedades Andinas. En MURRA, J. V. (ed.), Formaciones Económicas y Políticas del Mundo Andino, 59-116 pp. Ed. Instituto de Estudios Peruanos. Lima, Perú.

OTTONELLO DE REINOSO, M. \& B. RUTHSATZ. 1982. Environment, human settlement, and agriculture in the Puna de Jujuy, Argentina: a case study of land-use change. Mountain Research and Development 2: 111-126. https://doi.org/10.2307/3672937.

PAZ, R., F. SOSA VALDEZ, H. LAMAS, F. ECHAZÚ \& L. CALIFANO. 2012. Diferenciación social y procesos de mercantilización en los campesinos de la puna jujeña (Argentina). Estudios del Trabajo 43-44: 49-80.

PAZ, R., R. RODRÍGUEZ \& C. JARA. 2018. (Ed.) Sistemas comunales y explotaciones sin limites definidos: persistencia del campesinado en la Argentina. EDUNSE, Editorial Universitaria.

QUIROGA MENDIOLA, M. 2000. Condición actual de los pastizales de altura y sistema de pastoreo en los valles intermontanos de la Cordillera Oriental. Departamento de Iruya, Salta. Tesis de Maestría en Desarrollo de Zonas Aridas y Semiáridas Universidades del NOA, Salta, Argentina.

QUIROGA MENDIOLA, M. 2004. Highland grassland vegetation in the northwestern Andes of Argentina. Mountain Research and Development 24: 243-250. https://doi.org/10.1659/02764741(2004)024[0243:HGVITN]2.0.CO;2.

QUIROGA MENDIOLA, M. 2011. Sociedades y agroecosistemas pastoriles de alta montaña en la Puna. Departamento de Yavi, provincia de Jujuy, República de Argentina. Tesis Doctoral, Facultad de Ciencias Agropecuarias. Universidad Nacional de Córdoba, Córdoba, Argentina. Pp. 212.

RAFFAELLI, S. \& F. PÉREZ AYALA. 1999. Programa de manejo integrado de la cuenca del rio Iruya. Ed. COREBE. FMAM - OEA - PNUMA. Salta, Argentina.

RAGONESE, A. E. 1967. Vegetación y ganadería en la República Argentina. Colección Científica del INTA. Ed. Instituto Nacional de Tecnología Agropecuaria.

REBORATTI, C. 1998. El Alto Bermejo realidades y conflictos. Ed. La Colmena. Buenos Aires.

RIAT, P. 2012. Conocimiento campesino, el "monte santiagueño" como recurso forrajero. Trab. Soc. 19: 477-491. 


\section{Califano, L. M. - Manejo de especies forrajeras en Iruya (Salta, Argentina)}

ROSALES-BUSTAMANTE, E. P., C. D. C. LUNAMORALES \& A. CRUZ-LEÓN. 2009. Clasificación y selección tradicional de pitaya [Stenocereus pruinosus (Otto) Buxb.] en Tianguistengo, Oaxaca y variación morfológica de cultivares. Revista Chapingo. Serie Horticultura 15: 75-82. https://doi.org/10.5154/r.rchsh.2009.15.010.

SÁNCHEZ, M., P. MIRAÑA \& J. DUIVENVOORDEN. 2007. Plantas, suelos y paisajes: ordenamientos de la naturaleza por los indígenas Miraña de la Amazonía colombiana. Acta Amazónica 37: 567-582. https://doi.org/10.1590/S0044-59672007000400012.

SCARPA, G. F. 2000. Estudio etnobotánico de la subsistencia de los criollos del oeste de Formosa. Tesis Doctoral, Facultad de Ciencias Exactas y Naturales. Universidad de Buenos Aires, Argentina.

SCARPA, G. F. 2007. Etnobotánica de los Criollos del oeste de Formosa: Conocimiento tradicional, valoración y manejo de las plantas forrajeras. Kurtziana 33: 153174.

STURZENEGGER, O. 1982. Área de la selva TucumanoOranense. San Andrés: Actividades de subsistencia tradicionales y ritual propiciatorio. Documenta Laboris 27. Ed. Programa de Investigaciones sobre Epidemiología Psiquiátrica, CONICET. Buenos Aires, Argentina.

SUÁREZ, M. E. 2014. Etnobotánica wichi del bosque xerófito en el Chaco Semiárido salteño. Ed. Autores de Argentina. Buenos Aires, Argentina.

THE PLANT LIST. 2013. A working list of all plant species diversity. Disponible: http://www. theplantlist. org/ (Consulta 10/2019).

TOLEDO, V. 2002. Ethnoecology. A conceptual framework for the study of indigenous knowledge of nature. In: STEPP, R., F. WYNDHAM \& R. ZARGER (eds.), Ethnobiology and biocultural diversity, pp. 511-522. University of Georgia. Athens, Georgia, USA
TOLEDO, V. M. \& N. BARRERA BASSOLS. 2008. La memoria biocultural: la importancia ecológica de las sabidurías tradicionales, vol. 3. Ed. Icaria. Barcelona.

TORRADO, S. 1981. Sobre los conceptos de "estrategias familiares de vida" y "proceso de reproducción de la fuerza de trabajo". Notas teórico-metodológicas. Demografía y economía 15: 204-233. https://doi.org/10.24201/edu.v15i02.512.

TROLL, C. 1935. Los fundamentos de las civilizaciones Andinas y del Imperio Incaico. Revista Universitaria 8: 127-83.

TROLL, C. 1973. High mountain belts between the polar caps and the equator: their definition and lower limit. Arctic and Alpine Research 5: 19-27.

TROPICOS.ORG. 2019. Missouri Botanical Garden [online]. Disponible: http://www.tropicos.org/ (Consulta 05/10/19).

VAN KESSEL, J. 2000. La tecnología simbólica en la producción agropecuaria andina. En: VAN KESSEL, J. \& H. LARRAÍN BARROS (ed.), Manos sabias para criar la vida. Tecnología andina. Simposio del $49^{\circ}$ Congreso Internacional de Americanistas. Ed. Abya-Yala. Quito.

VENTURA, B. \& J. B. BELARDI. 2001. When clouds cover the woods: Etnoarchaeology in the Yungas of Salta, Argentina. En: KUZNAR, L. (ed.), Etnoarchaeology of Andean South America Contributions to Archaeology Methods and Theory, pp. 67-83. Etnoarchaeological Series, 4. International Monographs in Prehistory Ann Arbor, Michigan.

VILlAGRÁN, M. C. \& R. V. CASTRO. 1997. Etnobotánica y manejo ganadero de las vegas, bofedales y quebradas en el Loa superior, Andes de Antofagasta, Segunda Región, Chile. Chungara 29: 275-304. 
